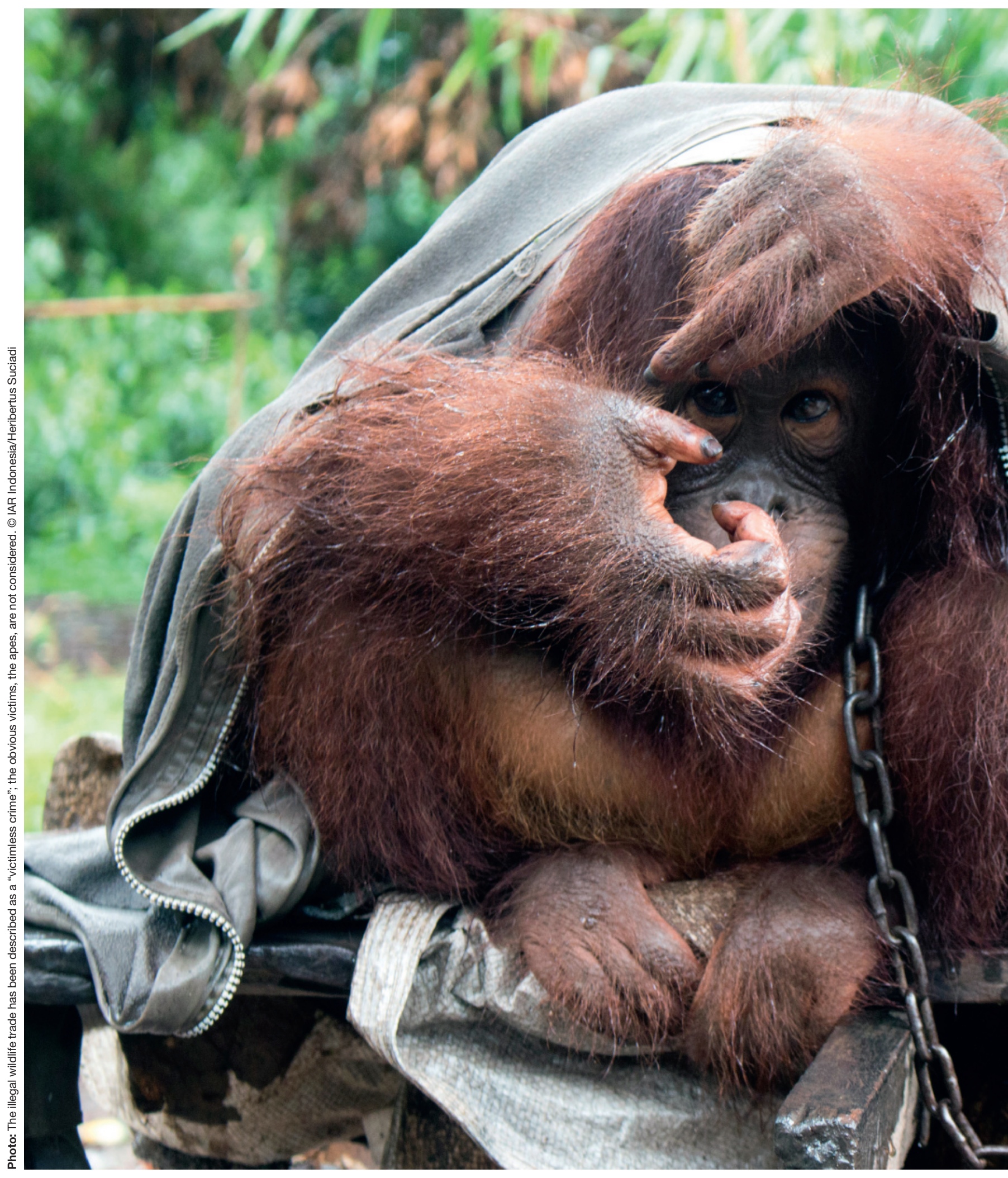




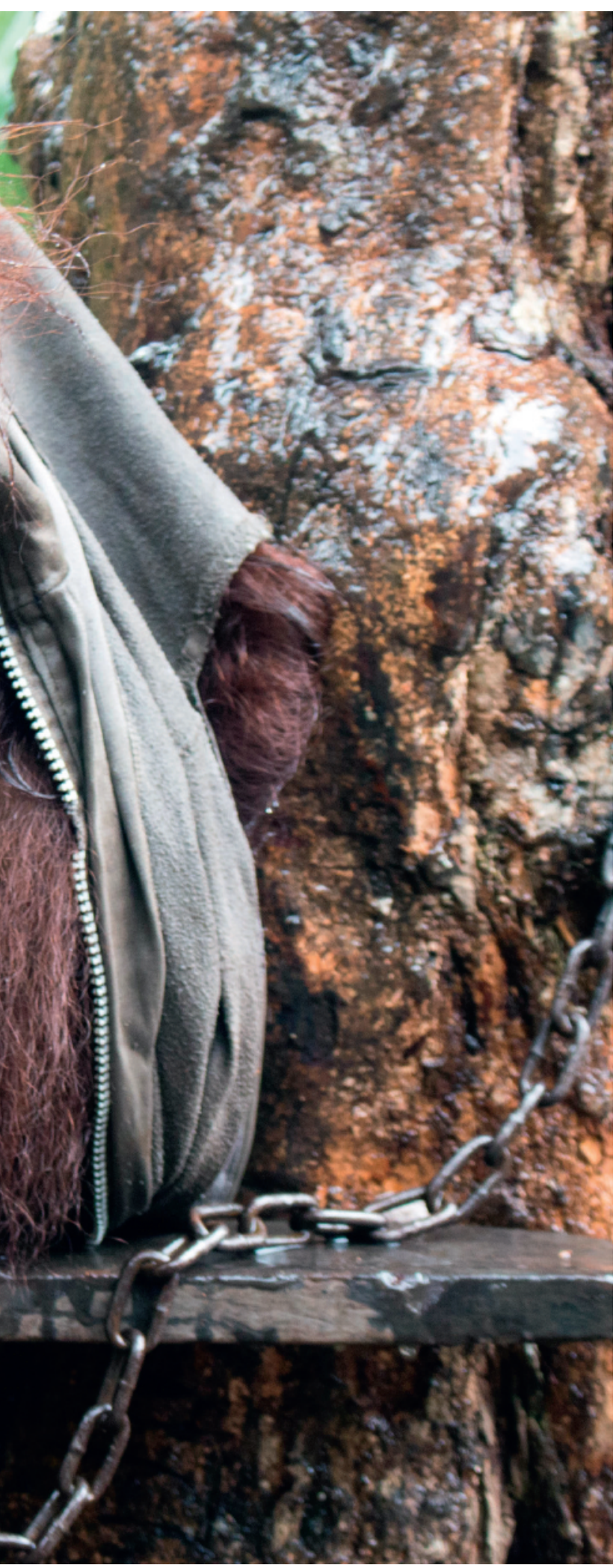

CHAPTER 4

\section{Drivers of the Illegal Trade in Live Apes}

\section{Introduction}

International trade in live apes is permitted only under conditions articulated in the widely ratified Convention on International Trade in Endangered Species of Wild Fauna and Flora (CITES) (CITES, 1973). The trade that takes place illegally can involve close cooperation between hunters, sellers, transporters, buyers and consumers-including audiences and pet owners. The transactional crimes between these sets of actors have been described as "victimless" because both buyers' and sellers' needs appear to be met without harm to either, which renders these violations difficult to combat (Felbab-Brown, 2017, p. 31; Sollund, Stefes and Germani, 2016, p. 6). From this perspective, the obvious victims-the apes-are not considered. 
Evidence suggests that most live ape sales are initiated over social media, that most trafficked apes are young and transferred by air, and that demand comes mostly from private collections.
While Chapter 3 of this volume examines the socioeconomics of the trade in ape meat and parts, this chapter focuses on key drivers of the live ape trade. It comprises four main sections. The first section considers the demand for apes from zoos and wild animal parks in China, whose economic growth has been accompanied by an increase in the number of its zoological collections. The second section studies the demand for apes in the marketing and entertainment industries-including film, television, advertising and circuses-in the United States and Thailand. Specifically, it reviews factors that have led to a decrease in the use of captive apes in the entertainment industry in the United States. The following section explores the demand for orangutans as pets in Indonesian Borneo. As interviews with former ape owners reveal, misconceptions about these animals and their needs motivate some people to "save" young orphans after their mothers are killed. This section also discusses the thriving pet markets of Eastern Europe, the Middle East and former Soviet states (see Box 4.2).

The final section analyzes the role of social media as an enabler of the illegal trade in live apes. It identifies various ways in which online platforms influence demand, in particular by conferring value on ape ownership, providing access to the market and engaging new audiences. It also considers how non-governmental organizations are working with social media companies to curb online trafficking in wildlife, including by educating social media users. The section concludes by suggesting alternative and supplementary avenues for engagement with companies and consumers, as well as broader demand reduction approaches.

The key findings include:

- By cooperating with global zoological associations to enhance the welfare and well-being of their wild-caught apes,
Chinese zoos could reduce their ape mortality rate and, consequently, the demand for more apes.

- Despite significant knowledge gaps regarding the scale of the illegal trade in live apes, evidence suggests that most sales are initiated over social media, that most trafficked apes are young and transferred by air, and that demand comes mostly from private collections.

- In Kalimantan, in Indonesian Borneo, where more than 100 captive orangutans are rescued every year, local residents tend to capture young orangutans opportunistically, such as after their mothers are killed for crop-raiding. They seek recognition for "saving" the orphans and do not fear legal consequences although they know orangutans are protected under the law.

- While some social media companies, such as Instagram, are monitoring images taken with wildlife, blocking access to posts that appear to sell protected species, and educating users about violations, they could have more of an impact by providing law enforcement with the details of users who violate wildlife legislation and targeting dedicated campaigns at the main potential purchasers.

- Biased and inaccurate representations of apes can affect people's perceptions of their prevalence and thus influence how concerned they are about a species' survival and how willing they are to support conservation efforts.

\section{Apes in China's Zoos and Wild Animal Parks ${ }^{1}$}

The increasing number of zoos and animal parks in China has fueled the demand for live apes from outside China. Indeed, China is often cited as the primary destination 
country in the trade (Dingfei, 2014). In the Chinese context, apes are typically found in two different types of facilities:

- "zoos," which tend to be owned and managed by the municipal or regional government; and

- privately owned "wild animal parks" (or "safari parks") and circuses.

Zoos are found in most major Chinese cities. They are generally small and typically charge low admission fees-on average US\$3. Many, including Kunming Zoo in Yunnan province and Fuzhou Zoo in Fujian province, were built on undesirable terrain, such as hills or mountains deemed unsuitable for more profitable construction. In contrast, wild animal parks, such as Hangzhou Wild Animal Park in Zhejiang province, are usually located at considerable distances from cities, occupy vast areas of suburban land, and are built and maintained with substantial budgets, while charging admission fees of US $\$ 36$ on average. Whereas many city zoos were established many years ago, wild animal parks have proliferated more recently, especially in wealthier coastal cities. Recent openings include those of Xiamen Central Africa Shiye Wildlife Park in Fujian province in 2016; Taizhou Bay Wildlife Park in Zhejiang province in 2018; and Jinniu Lake Wild Animal Kingdom in Jiangsu province in 2019. Others are under development, including Chimelong Qingyuan Forest Resort in Guangzhou province, which is scheduled to open in 2021.

It is difficult to estimate with any accuracy how many such facilities are in operation, not least because they are regulated by different government departments. The Chinese Ministry of Housing and UrbanRural Development oversees city zoos, but the extent of regulations and enforcement in this area is limited. The ministry also hosts the Chinese Association of Zoological
Gardens, a unifying body that counts approximately 155 zoos and wild animal parks as voluntary members but operates without any accreditation process (CAZG, n.d.). The Chinese State Forestry and Grassland Administration - which also houses the CITES Management Authority-has jurisdiction over wild animal parks and regulates the holding of all exotic species, including those in city zoos (Zuo, 2017).

The conflicting regulatory regimes of these agencies have given way to gray areas. The Ministry of Housing and Urban-Rural Development was instrumental in banning animal performances in China in 2011, for example, but it is unable to regulate performances in wild animal parks, which are administered by the Forestry and Grassland Administration. Further, some city zoos historically subcontracted animal performances to private companies, which rent space or arenas on city zoo property. Such "enclaves" also fall outside the jurisdiction of the Ministry of Housing and Urban-Rural Development; as a result, animal performances can technically continue until the expiration of contracts that were signed before 2011. In practice, pressure from the central government has led to the retirement of great apes from all but a handful of animal shows, all of which are privately operated.

The drive to establish new wild animal parks is fueled by China's economic and cultural evolution. Forty years of reforms have led to strong economic growth, lifting 800 million citizens out of poverty and transforming China into an upper-middle-income nation (International Monetary Fund, 2018). Raised in an era of economic prosperity, today's Chinese have far greater spending power than prior generations: between 2010 and 2020 alone, urban consumers' annual disposable income was expected to double to about US $\$ 8,000$ (Atsmon et al., 2012). As a result, they are willing and able to spend more time on leisure activities, including 
Photo: In contrast to more traditional forms of entertainment, in Asia, leisure spending has pivoted towards novel experiences, including theme parks with wild animal attractions. Guangzhou Chimelong Tourist Resort comprises five leisure attractions, including a wild animal park, bird park, water park, circus and amusement park, plus three hotels. (c) PEGAS tourism, as evidenced by an annual increase of $10 \%$ in consumer expenditure in the leisure sector since 2011. Now the second-largest in the world, China's leisure industry was valued at US $\$ 479$ billion in 2017 (OC\&C Strategy Consultants, 2017).

Leisure spending in China has shifted towards novel experiences, including theme parks (OC\&C Strategy Consultants, 2017). Most new wild animal parks feature themepark rides or are built around resorts that comprise multiple parks, hotels and associated infrastructure. A prime example of the latter model is the Guangzhou Chimelong Tourist Resort, which comprises five leisure attractions, including a wild animal park, bird park, water park, circus and amusement park, plus three hotels (Chimelong, n.d.). The neighboring Zhuhai Chimelong International Ocean Resort has four hotels, a circus and the largest aquarium in the world. The Chimelong Group welcomed

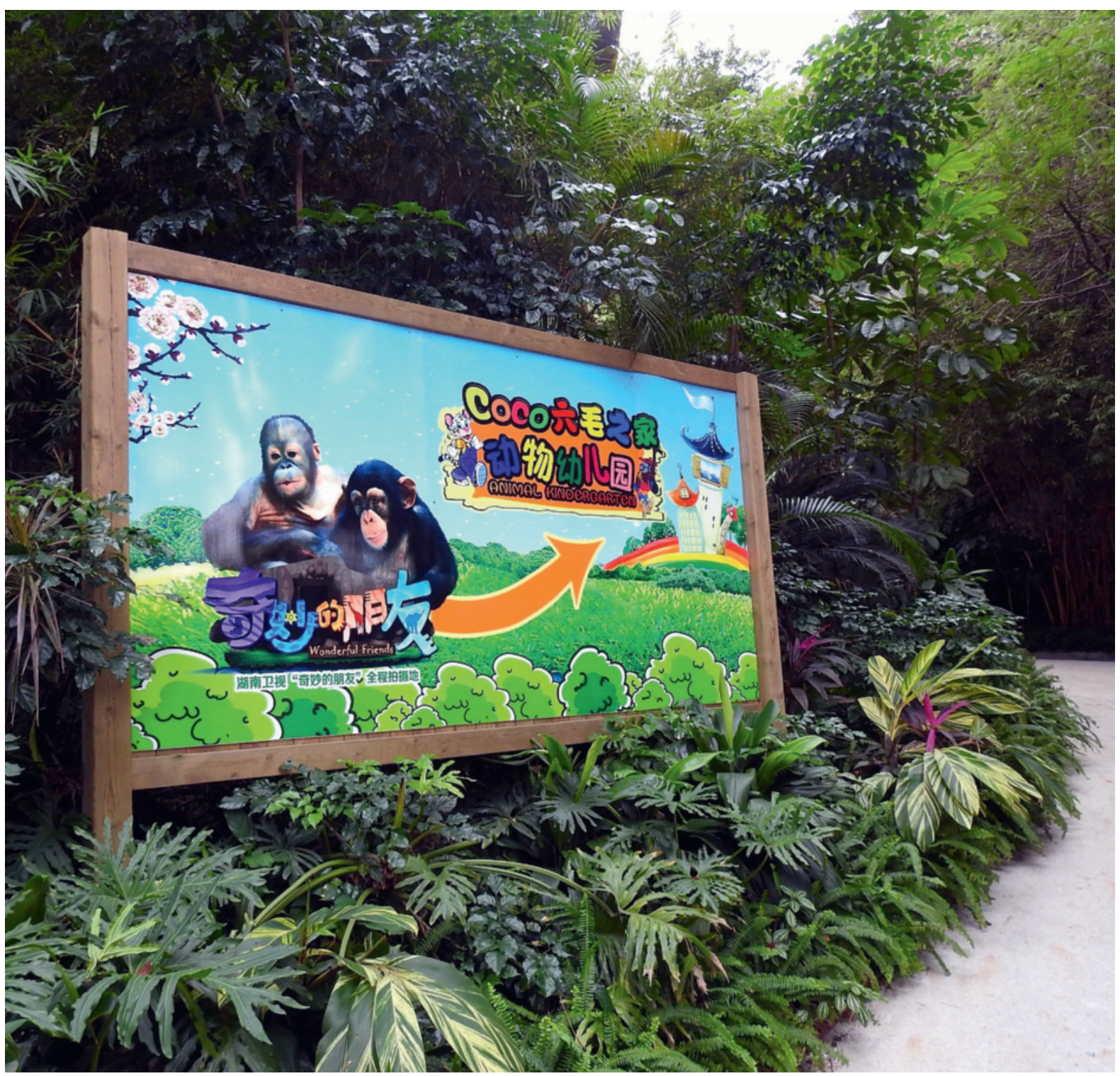


about 31 million visitors to these various attractions in southern China alone in 2017-almost one-fifth of the number of people who visited all Walt Disney parks and resorts worldwide during the same year. Chimelong visitors increased by $13.4 \%$ over the previous year, at roughly twice the rate of Disney visitors (TEA/AECOM, 2017). The lack of accessibility is the key barrier to increased growth in the leisure sector, a challenge that is being addressed through widespread construction of additional, multithemed wild animal parks (OC\&C Strategy Consultants, 2017). In addition to the resort model, the government incentivizes the development of wild animal parks as elements of entirely new cities and towns.

\section{Competition-induced Fraud and Ape Trafficking}

Establishing a new wild animal park is a commercial gamble, especially in areas that are already saturated with similar parks. Three new private wild animal parks were initially projected to open by 2020 in Jiangsu province, eastern China; all were expected to compete with one another and with the well-established city zoo. As of September 2019, one park had opened and a second one was under construction. It is unlikely that all three parks will be completed or prove to be financially viable.

As part of the competition, the pressure to acquire animals is high. Small city zoos with limited budgets feel this burden as they struggle to compete with large and private wild animal parks, as do smaller private operations. One zoo in Yulin, Guangxi province, displayed inflatable penguins in 2017; a few years prior, the Louhe Zoo in Henan province made international headlines by presenting a Tibetan mastiff dog as a lion (Chiu, 2013; Shen, 2017).

Since the supply of endangered species is limited, most zoos and wild animal parks rely on Chinese animal dealers to acquire specimens for display. Dealers tend to turn to illegal sources, as was the case between 2007 and 2012, when more than 100 wildcaught chimpanzees from Guinea were trafficked to China in a CITES permit scam (see Box 6.1). The most active traffickers of wild-caught, live great apes operate in Tianjin, Hebei province, and in Dalian, Liaoning province. ${ }^{2}$

\section{Limited Data on the Imports and Market Value of Apes}

The financial costs associated with acquiring apes have been the subject of intense speculation. Some gibbon species are endemic to China and there is little evidence of largescale acquisitions of gibbons from other nations. Although Chinese zoos show considerable demand for gorillas, there is no proof that any have been imported illegally, nor is it possible to assess the costs associated with such imports. The CITES Trade Database indicates that ten "captive-bred" live gorillas were imported from Guinea in 2010, yet there is no evidence that this transaction took place (CITES, n.d.-h). Ammann (2014) reports that staff members at a zoo in central China, who had prepared signage for a purported gorilla exhibit, disclosed that four gorillas had arrived in 2010 but were euthanized after two were found to be positive for hepatitis; one had bitten and infected a keeper. These reports may have confused gorillas with chimpanzees, however, as the Chinese language uses ape terms interchangeably and Chinese people are generally unfamiliar with ape species. An article in one newspaper used the Chinese characters for gorilla, chimpanzee and orangutan to describe chimpanzees (Wen Naifei and Tan Siqi, 2013).

In contrast, orangutans are known to have been imported into China, the majority of them legally (CITES, n.d.-h). Historically, 


\section{In China, zookeeping is not professionalized, and} while zoology and veterinary programs exist at universities, they are not focused on captive animal care and barely cover non-domestic animals. they were transferred from zoos in the United States; in the 1990s, they came from Taiwan, where dozens were confiscated by the government. Many had been smuggled into Taiwan for sale in the pet trade, as demand had been fueled by a popular Taiwanese television show that featured a young orangutan (Leiman and Ghaffar, 1996). Today, most orangutans in China are controlled by a single owner who leases them to different zoos although costs and lease agreements remain undisclosed.

Chimpanzees are the only apes for which documentation shows large-scale imports to Chinese zoos. Various reports have speculated on the market value of chimpanzees in China, with values ranging from US $\$ 12,500$ to US\$30,000 per individual (Clough and May, 2018). Dealers appear to charge each zoo a different price, most probably in line with sums that the highest bidders are prepared to pay.

Contrary to common assumptions, great apes are less popular with Chinese zoo visitors than are large carnivores. As tigers are especially important in Chinese culture, many wild animal parks house dozens or even hundreds of captive-bred tigers; the Xiongsen Bear and Tiger Mountain Village in Guilin, Guangxi autonomous region, counts about 1,80o tigers. Some parks, such as Harbin Siberian Tiger Park in Heilongjiang province, house only tigers and no other animal species. Many are farmed specifically for trade in Chinese medicines (Knowles, 2016). Among the primates, macaques carry particular cultural significance; in homage to the Ming dynasty novel Journey to the West, they usually live in elaborate mountain-style exhibits, while great apes are confined to much smaller enclosures in spite of their greater spatial and cognitive needs (Cheng'en Wu, 1993; Gallo and Anest, 2018). The ongoing interest in acquiring great apes may be driven less by public demand than by zoo and wild animal park managers' passion projects. It is likely that several Chinese institutions that recently acquired or expressed interest in procuring great apes did so for sentimental reasons attributed to senior staff.

\section{Barriers to Adequate Welfare and Well-being of Captive Apes}

In China, zookeeping is not professionalized, and while zoology and veterinary programs exist at universities, they are not focused on captive animal care and barely cover non-domestic animals. As a consequence, the staff in China's zoos and wild animal parks, especially the smaller and less well-resourced ones, generally lack expertise in the care of great apes. In one seemingly extraordinary case, wild animal park staff members who were not aware that orangutans are primarily frugivorous in the wild recorded buckets of fried chicken and cans of Red Bull as diets for these apes. In other cases, staff introduced two flanged males to one another, which resulted in serious injury. Chimpanzee injuries are common and deaths occur occasionally, as there is little understanding of chimpanzee behavior and sociality in the wild. Of the three institutions that house legally acquired gorillas, two have a lone silverback, contrary to natural social structure (Robbins et al., 2004). ${ }^{3}$

The acquisition of wild-caught chimpanzees from the same or similar habitats has caused particular problems for their management in China. Inbreeding is thought to be the predominant issue: interbreeding closely related founders could be the cause of high recorded rates of stillbirth and infant mortality across the captive population. The situation is likely to persist as long as zoo managers decide on transfers and exchanges with other zoos, which typically involve deals with neighbors and friends (Banes et 
al., 2018). Zoos may also be encouraging inbreeding by offering staff bonuses for offspring born under their care, which can cause further fetal and infant mortality as well as the hybridization of distinct ape species.

The bulk of these challenges are compounded by a lack of access to information. The Chinese government blocks or censors many online animal welfare and husbandry resources, though perhaps not always intentionally so - such resources might simply contain keywords on a blacklist. Resources of the World Association of Zoos and Aquariums (WAZA) are generally inaccessible because the Association recognizes Taiwan as an independent country (WAZA, n.d.). For this reason, Chinese zoos cannot easily affiliate with WAZA. In recent years, several Chinese zoos have individually expressed interest in joining the European Association of Zoos and Aquaria (EAZA) as observers; gorillas were sent from Rotterdam to the Shanghai Zoo in 1993 and 2007, as a result of EAZA agreements. EAZA has endorsed a proposal to send additional gorillas to at least one Chinese zoo. Chinese zoos will not be able to become accredited members of the US Association of Zoos and Aquariums (AZA) until their standards are considered adequate for accreditation.

Language barriers also stand in the way of better ape welfare in China. While AZA has made many of its online resourcesincluding animal care manuals-accessible to non-members, none are published in Chinese. ${ }^{4}$ Machine-translation software is commonly available and used in China, but all text to be translated must pass through a government censor, which may lead to incomprehensible translations. Machine translations of critical care information, such as veterinary guidance or drug dosages, cannot be relied upon as accurate; further, many drugs are unavailable in China. Of a total population of 1.4 billion, only around 10 million people in China are thought to be able to use English (VoiceBoxer, 2016; Yang, 2006). The lack of access to Chineselanguage resources is therefore a considerable barrier to education.

Another significant challenge facing Chinese zoos is the West's critical attitude, which is often based on false allegations or gross generalizations (Banes et al., 2018). Few Western organizations have been willing to engage constructively with Chinese zoos to provide training, improve conditions or address illegal trade. Antagonistic approaches are common, as evidenced by media portrayals of universally poor conditions and practices. Attempts to quantify the extent of the illegal trade-based on information that Western non-governmental organizations (NGOs) collected during surreptitious visits to Chinese zoos-have also proven problematic: the common assumption that all infant great apes were wild-caught, for example, is erroneous and has led to incorrect calculations of the scale and extent of illegal acquisitions. Such rash judgments have undermined Chinese zoo managers' confidence in Western colleagues. The Great Ape Survival Partnership (GRASP) exacerbated this problem in 2014, when it released a Facebook post about a "wild-caught," "male" orangutan at a particular facility. The infant in question was actually legally bred in captivity, female and housed at a different zoo, yet the post attracted hundreds of negative comments and reactions from its Western audience (Banes et al., 2018).

In 2018, two major collaborative efforts were made to enhance orangutan welfare in China. The China National Orang-utan Workshop was hosted by the Chinese Association of Zoological Gardens from 25-30 October, at Nanjing Hongshan Forest Zoo in Jiangsu province (Sacramento Zoo, 2018), and comprised an international delegation of 136 attendees from Chinese and US zoos. A Chinese-language Orang-utan Husbandry Manual was concurrently published and 


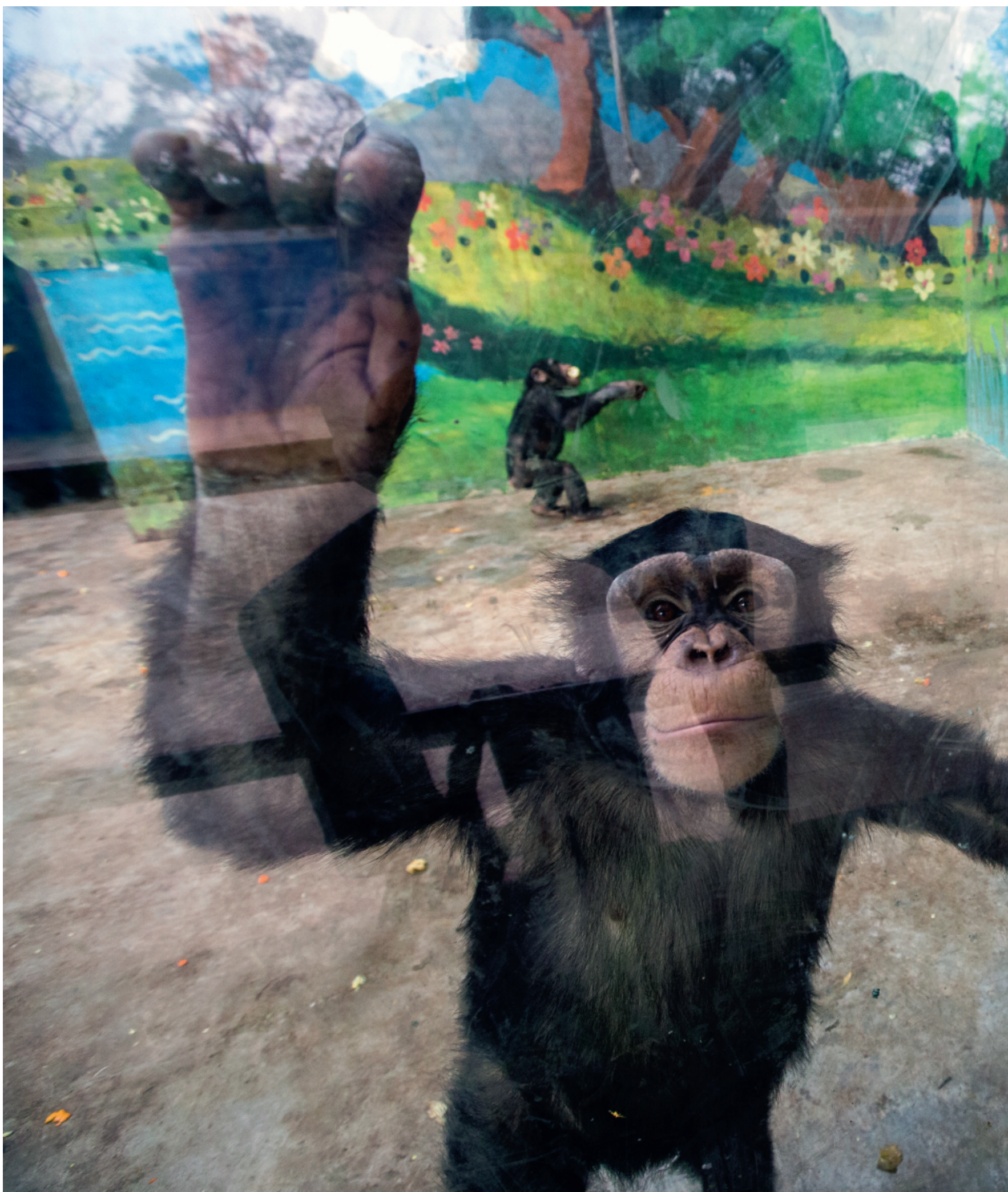


Given that

attitudes towards

animals are changing

in China, pressure

for zoos to improve

animal welfare

standards is more

likely to come from

the Chinese public

and government than

Western actors.
Over the past three decades, however, interest in animal rights has steadily gained ground. The Chinese Academy of Social Sciences was among the first to introduce the concept into Chinese academia (Yang, 1993). Some Chinese scholars, however, dismissed this vision as a Western corruption (Zhao, 2002). Indeed, Western ideas appear to have had some influence-both through Western media and the activities of Western NGOs in China-but a domestic movement for animal protection has also grown substantially (Li and Davey, 2013). Although one four-year study concluded that most Chinese people do not view animals as selfaware or sentient, a second survey-this one more focused on urban residents, and thus the growing middle class-found that $61.7 \%$ of respondents said that all animals should be protected (Askue et al., 2009; Zhang, Hua and Sun, 2008). More than half of the respondents $(52.6 \%)$ said that animals are equal to humans and deserving of respect and protection; $81.3 \%$ expressed support for wildlife conservation (Zhang, Hua and Sun, 2008). Chinese zoos and wild animal parks could therefore play an important role in conservation education. Every year, an estimated 100 million people or more visit member institutions of the Chinese Association of Zoological Gardens, which represent only a small proportion of all zoos and wild animal parks in China (Askue et al., 2009).

Given that attitudes towards animals are changing in China, pressure for zoos to improve animal welfare standards is more likely to come from the Chinese public and government than Western actors. In one survey, of things enjoyed most in theme parks, $18 \%$ of parents were interested in seeing live animals while only $2 \%$ wanted to see animal performances (OC\&C Strategy Consultants, 2017). As noted above, the use of animals in circus-style shows has been illegal in city zoos since 2011; efforts to enforce related legislation appear to be intensifying. Although their use continues in private wild animal parks and circuses due to the above-mentioned conflicts in regulatory regimes, attendance at some performances is reportedly at a historic low (Agence France-Presse, 2018). As mentioned, great apes have also been eliminated from most performances following pressure from the central government.

In addition, animal abuse has drawn growing public opprobrium on social media in recent years. Repeated acid attacks on bears at the Beijing Zoo in 2002 were met with widespread condemnation; one Internet forum apparently received more comments on these incidents than on any other domestic or international event (Shuxian, $\mathrm{Li}$ and $\mathrm{Su}, 2005)$. In 2018, a keeper was fired from a zoo in Wuhan, in Hubei province, after a viral video showed him physically abusing a giant panda; another was terminated from an aquarium in Dalian, in Liaoning province, after being filmed putting lipstick on a beluga whale (Chan, 2018; Zhou, 2018). As discussed in the next section, the US experience indicates that such shifts in public perception influence the use of animals and, ultimately, the trade in wildlife.

\section{Apes in Advertising and Entertainment in the United States and Thailand}

This section reviews changes in the use of apes in the marketing and entertainment industries in the United States and Thailand. The US case focuses on the use of apes in film, television and advertising; the Thai case examines their role in circus-type facilities. The findings could inform efforts to curb the use of apes in these sectors in other countries. 


\section{Great Apes in Movies, TV and Commercials in the United States}

Humans have always been fascinated by wild animals, and great apes in particular. In part, this interest is due to our physical and behavioral similarity to non-human apes. The most famous early motion picture to depict a great ape was the 1932 film Tarzan the Ape Man, in which a chimpanzee named Jiggs played the role of Cheetah (The Atlanta Constitution, 1938; Van Dyke, 1932). Since then, great apes have been popular standins as human caricatures in film, television shows and commercials. In 1951 a chimpanzee named Peggy starred alongside Ronald Reagan in his most popular movie, Bedtime for Bonzo (De Cordova, 1951; King, n.d.). An orangutan named Manis played the role of Clyde alongside Clint Eastwood in the 1978 movie Every Which Way but Loose (Fargo, 1978). Chimpanzees were featured in the popular 1970s spy-parody television series Lancelot Link: Secret Chimp, and later became fixtures of Super Bowl commercials for large US brands, such as CareerBuilder, Castrol, E*TRADE and Pepsi (Pollack, 2016; Shields, Jones and McKimson, 1970).

Unlike the early years, when chimpanzees who appeared in US films, TV shows and ads were all wild-caught, the great ape "performers" of recent years are captive-born chimpanzees and orangutans. Most were born in entertainment facilities or purchased from the Missouri Primate Foundation (MPF) in Festus, Missouri. While MPF no longer breeds or sells, it still houses chimpanzees (ChimpCARE, n.d.-a; PETA, n.d.). The cost of purchasing a great ape is not typically advertised and not likely to be standardized, but there are some indicators of their market value. A former trainer named Judie Harrison reported that she purchased an infant male chimpanzee from MPF for
US $\$ 45,000$ in 2002 (Schapiro, 2009a). In 2015, trainer Steve Martin valued a male chimpanzee at US\$60,000 and a female one at US $\$ 25,000,{ }^{5}$ possibly based on physical characteristics, although female chimpanzees have generally sold for higher amounts than males in view of their breeding value. During the 1980 and 1990s in the United States, a chimpanzee typically cost US\$20,000-50,000 (S. Ross, personal communication, 2019).

Much more is known today about the behavior and developmental needs of great apes than in the heyday of ape stardom. Numerous studies on ape social behavior and cognition have demonstrated that great apes are highly intelligent and emotional animals capable of psychological suffering. Researchers have observed that after experiencing traumatic events, chimpanzees may exhibit signs of post-traumatic stress disorder and depression, and that they respond to the death of a relative with behaviors similar to those of humans, including mourning (Balter, 2010; Bradshaw et al., 2008; Ferdowsian et al., 2011).

In order to be trained, chimpanzees and orangutans are taken from their mothers during infancy, a practice that causes distress in the mother, produces anxiety in the infant and impairs normal infant development (Baker, 2005). Training commonly involves physical abuse. Although apes can easily live to the age of 45 , they are typically retired when they reach adolescence, around the age of 12, due to their great size and strength, and because their behavior may be unpredictable (Courtenay and Santow, 1989). Many former "performers" have difficulty integrating into conspecific groups after retirement, as they exhibit socially dysfunctional behaviors that are attributed to a lack of proper mothering and isolation from other apes (Freeman and Ross, 2014; Jacobsen et al., 2017).

Now that US audiences are generally better informed about great apes, their use 


\section{BOX 4.1}

\section{Reduction in the Use of Apes in Entertainment in the United States: Advocacy, Computer- Generated Imagery (CGI) and Exhibitor Attrition}

\section{Great Ape Advocacy Campaigns}

As understanding of great apes has grown from field research, and documentation of physical abuse by great ape trainers has been publicized in major campaigns starting in 1996 and 2003 by animal protection groups - together with two highlypublicized attacks on humans by "pet" chimpanzees in 2005 and 2009-public perspectives shifted on the use of apes for entertainment in the US (Friends of Washoe, n.d.; Gang, 1996; Newman, 2009; Primate Info Net, 2005; Roderick, 1990; Schapiro, 2009b).

From 2005, People for the Ethical Treatment of Animals (PETA) led focused education campaigns aimed at sensitizing the public to the plight of great apes used in entertainment, including through letterwriting initiatives targeting filmmakers and companies that were exploiting chimpanzees and orangutans (PETA, n.d.). Having garnered support from Hollywood celebrities Anjelica Huston and Pamela Anderson, PETA successfully lobbied more than 40 advertising agencies-including major players such as BBDO, DDB, Grey Group, McCann Erickson (now McCann) and Young and Rubicam (now VMLY\&R) to ban the use of great apes in their advertising (Ad Age, 2012). Several companies, including AT\&T, Capital One, Dodge, Pfizer and Traveler's Insurance, pulled TV ads that featured chimpanzees and orangutans after talks with PETA and the Washington State-based organization Chimpanzee Sanctuary Northwest (Mullins, 2010; Nudd, 2010). PETA reported that between 2009 and 2016, 40 US television commercials featured great ape "performers"; 25 of them were pulled off the air soon after companies learned about the controversy associated with using great apes in advertising. ${ }^{6}$

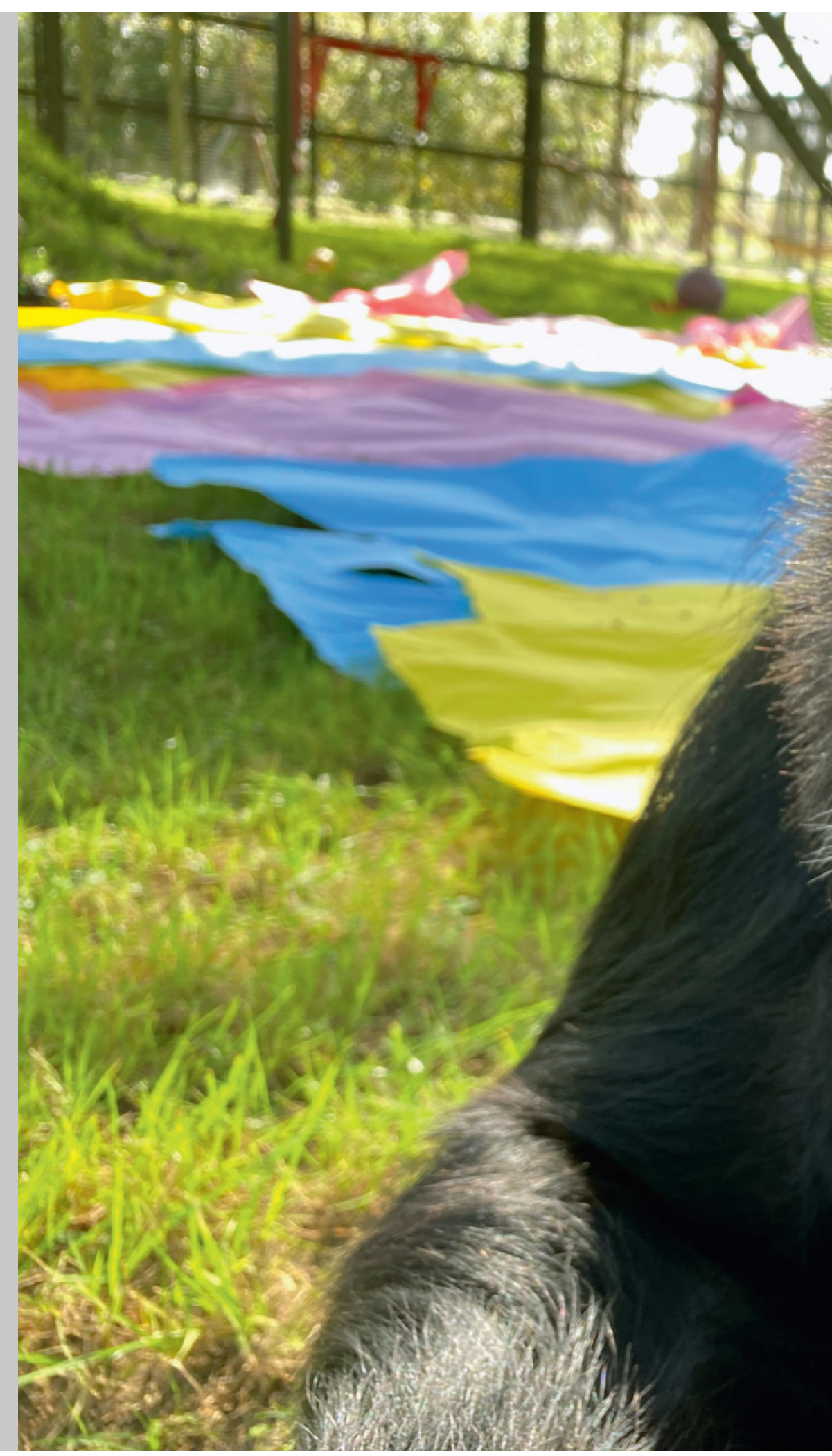




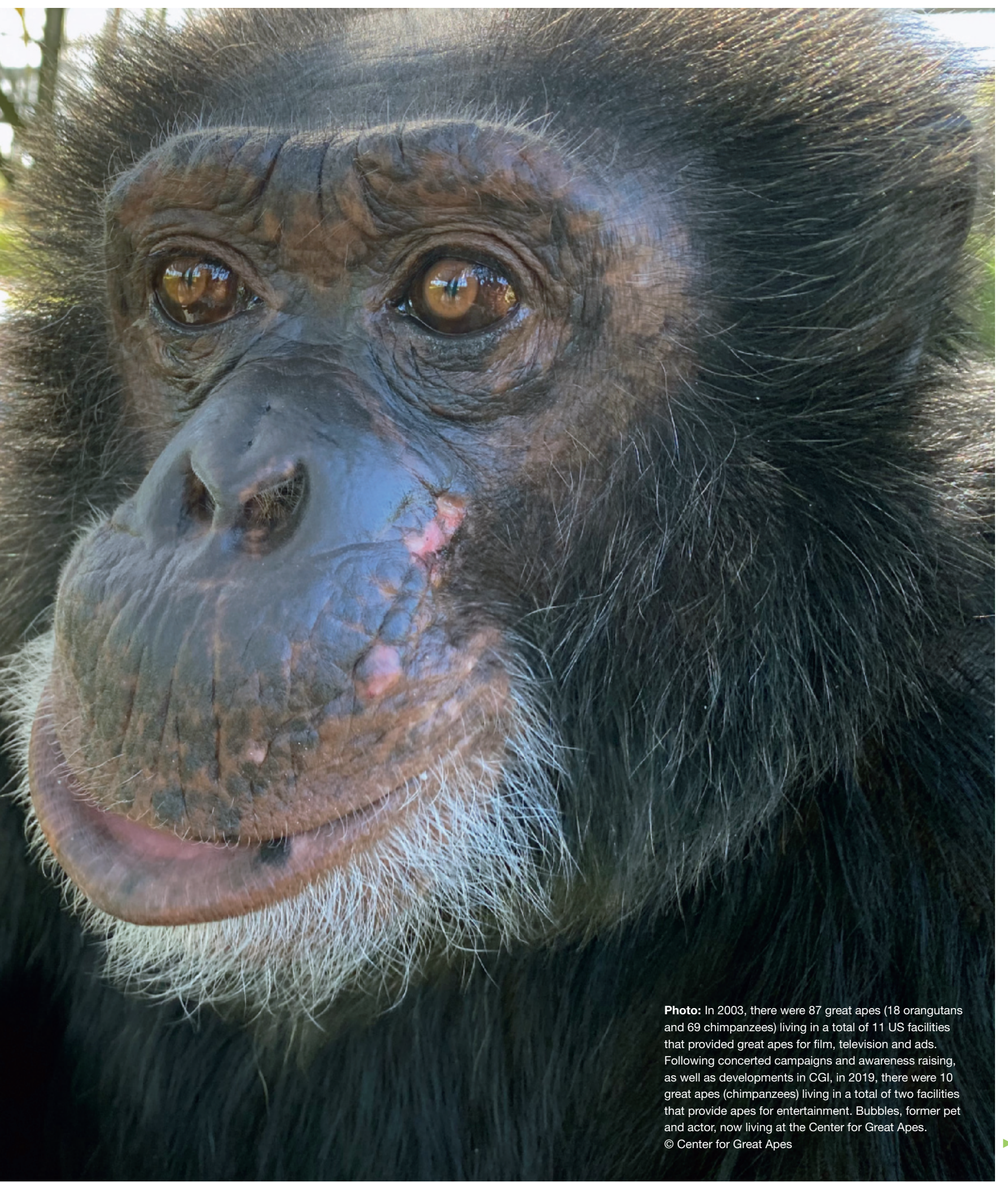


Another major force responsible for shifting public opinion and corporate behavior regarding the use of great apes in entertainment and marketing was the Chimpanzee Species Survival Plan (SSP) of the Association of Zoos and Aquariums (AZA) (Lincoln Park Zoo, n.d.). The SSP wrote more than 80 letters to advertising agencies and other companies between 2002 and 2014, and engaged with many of the individuals involved in breeding, training and filming apes. In many cases, the companies and individuals confirmed that they would end their use of apes as a consequence of this engagement.

Scientists and conservationists have also served as advocates for the rights of great apes. In 2009, the Los Angeles Times published an opinion piece by Jane Goodall in which she condemned the use of great apes for entertainment, following an attack involving a performer-turned-pet chimpanzee in Stamford, Connecticut (Goodall, 2009). Studies published in 2008 and 2011 show that the inappropriate portrayal of chimpanzees in film and television programming hinders conservation efforts (Ross et al., 2008; Ross, Vreeman and Lonsdorf, 2011; Schroepfer et al., 2011; see Box 4.3). Following the first study's release, the board of directors of the AZA issued a white paper recommending that the use of all ape species in commercial entertainment and advertising be eliminated (AZA, 2008). Stephen Ross of the Lincoln Park Zoo, who coauthored two of the aforementioned studies on chimpanzee depictions, subsequently launched Project ChimpCARE, which addresses the use of chimpanzees in entertainment (ChimpCARE, n.d.-b). As part of Project ChimpCARE and in collaboration with the Chimpanzee SSP, many former "entertainment chimpanzees" were moved to zoos and accredited sanctuaries. An entire compound of 14 "actor" chimpanzees moved to zoos in Houston, Maryland and Oakland in 2010 (Bender, 2010).

\section{Advancements in CGI}

The successes ape advocates have achieved in recent years were possible in part due to the development of realistic $\mathrm{CGI}$ animals in motion picture productions, which provides an alternative to live animal use. The first realistic CGI animal, a white owl, was debuted in the 1986 movie Labyrinth (Stuff, n.d.). Since then, CGI has been used to create hundreds of different animal species, including chimpanzees, gorillas and orangutans. The 2011 movie Rise of the Planet of the Apes was a game-changer for great apes and their advocates. Weta Digital created a chimpanzee named Caesar, the movie's central character, using CGI and motion capture, thereby demonstrating that CGI could seamlessly replace a live chimpanzee in a film (Weta Digital, n.d.). Since then, the visual effects companies that employed CGI to portray an enormous orangutan in the 2016 Jungle Book-including Pixar, Rhythm and Hues, and Disney - have contributed to major advancements in CGI technology, which benefits animals and allows for greater versatility and control in filmmaking
(Sims, 2016). In 2005, the director of Jim Henson's Creature Shop told the Los Angeles Times that studios often prefer to use CGI in place of live animals because it allows "complete control over the performance" (Covarrubias, 2005). Although it is still possible to tell that CGI apes are indeed CGI, technological advances will probably make that harder to discern. It is unclear, however, how such images will affect the perception of the status and welfare of apes.

\section{Attrition of Entertainment Providers}

According to a 2003 census conducted by the Great Ape Project in the United States, 87 great apes (18 orangutans and 69 chimpanzees) were living in a total of 11 facilities that provided great apes for movies, television shows and ads (Goodall et al., 2003). In April 2020, Project ChimpCARE reported that 11 chimpanzees were housed in two facilities that provide apes for entertainment (ChimpCARE, n.d.-a). These figures suggest that the number of great apes available for performances declined by $87 \%$ since the 2003 Great Ape Project census. The drop reflects two main trends: ape trainers have retired their animals and have not acquired infant apes to replace them, as was typical in previous years. Judie Harrison, who retired two chimpanzees named Mikey and Louie to the Little Rock Zoo in 2008, cited the cost of care as a reason for retiring the animals, who were no longer "working" because of their age (Anonymous, 2009). Steve Martin of Steve Martin's Working Wildlife told the Los Angeles Times, "with computers and animatronics and such, there's not as much demand for chimps and live animals anymore" (Covarrubias, 2005). The youngest and last "working" chimpanzee at his facility, Eli, was most recently featured in a production in 2016. Three years later, when Eli was nine years old, Steve Martin "retired" him to Wildlife Waystation, an unaccredited sanctuary with a history of problems. The sanctuary ceased operations about a year after Eli arrived, forcing hundreds of animals to relocate. Its closure illustrates problems associated with allowing trainers to select a retirement setting for animals, as they may choose the most affordable rather than the most appropriate option. Along with another former "actor" chimpanzee named Susie, Eli was subsequently moved to Lincoln Park Zoo in Chicago, an AZA-accredited facility, where the two are being integrated into a larger social group. 
as performers has become less palatable. Several factors have contributed to this shift, including advocacy campaigns by animal protection groups, advancements in computergenerated imagery (CGI) and exhibitor attrition (see Box 4.1). As a result, the entertainment and advertising landscapes have quickly changed in favor of great apes.

While it is no longer common to see great apes in movie and television productions in the United States, the practice of exploiting apes for entertainment has not been completely eradicated and is still very popular in other parts of the world. Even in the United States and Europe, images of great apes as clowns, displayed on outmoded greeting cards, are reminders of the days of "chimp shows." In 2017, a chimpanzeebonobo hybrid named Tiby, who lives in a circus facility in France, was featured in The Square, a Swedish film that received critical acclaim all over the world (Östlund, 2017). Regardless of recent advances, the appearance of just one great ape in a major film or popular television show has the potential to significantly affect how humans perceive the species.

\section{Orangutans in Thai Entertainment Facilities}

Whereas the demand for apes in the entertainment industry may have declined in the United States in recent years, the opposite is true for Thailand's entertainment sector, in which demand for orangutans has recently resurfaced, following a significant drop. ${ }^{7}$

From around 1990, the use of orangutans became widespread in both tourist and entertainment shows in Thailand. The larger operations strove to create a Disneylike experience, combining animal theme parks with shows and targeting families in particular, such as by offering family tickets (ticket sales account for about $60 \%$ of most parks' income) (Safari World, 2017; Silom Advisory Co., 2017). Some parks, including Safari World, hired specialists from the Singapore Zoo to design and set up animal acts (former Safari World employee, personal communication, 2018). One online ad for an orangutan "boxing show" still promises visitors comical acts in which apes in boxer outfits "dazzle" audiences "with their mathematical gifts" (Safari World, n.d.). Ticket holders are also given the opportunity to hold and have photos taken with apes.

By the late 1990s, wildlife conservationists and animal rights activists had become vocal on this use of orangutans. Some of them accused Thai animal theme parks and zoos of acquiring apes from traffickers who bought them from Indonesian poachers. They also alleged that trainers mistreated apes to encourage compliant behavior during shows and interactions with visitors. ${ }^{8}$ These outcries appeared to start reaching tourists from Japan, South Korea, the United States and Western Europe, as indicated by the absence of younger people from these countries among audiences at the shows. ${ }^{9}$ In late 2003, the queen of Thailand added her voice to the campaign, inspiring a national crackdown on wildlife crime, which involved raids on Safari World and other establishments (ENS, 2006). Apes were seized and DNA tests provided evidence to support the allegation that more than half of the orangutans at Safari World had been smuggled from Indonesia (Reuters, 2006; S. Changtragoon, personal communication, 2006). Separately, law enforcement arrested wildlife suppliers, including one who ran a holding facility and slaughterhouse outside Bangkok, where freezers were stocked with bear paws, tiger meat and a frozen baby orangutan. Asked about the dead ape, the owner alleged that some restaurants offered orangutan to select diners on special order, adding that they did so "rarely" (L. Tiewcharoeon, personal communication, 2016). 
Photo: From around 1990, the use of orangutans became widespread in both tourist and entertainment shows in Thailand. One online ad for an orangutan "boxing show" still promises visitors comical acts in which apes in boxer outfits "dazzle" audiences "with their mathematical gifts." In late 2003, DNA tests showed that more than half the orangutans at Safari World had been smuggled from Indonesia. Safari World. (c) PEGAS
These raids were widely covered by local and international media, which helped create momentum to clean up Thailand's tourism business. In Bangkok, for example, mahouts stopped parading elephants down the streets - as they had done every day for more than ten years-and instead moved them to sanctuaries. By the time Thailand hosted the 13th Conference of the Parties (COP) of CITES in October 2004, the government had acknowledged its role in a global problem
- at least at the senior level. Mid-level officials bristled at the criticism of Thailand and the increased work that was placed on them to eradicate the illegal trade. The prime minister offered to initiate a regional wildlife law enforcement network to stop cross-border trafficking; ministers of the Association of Southeast Asian Nations (ASEAN) who were responsible for implementing CITES agreed and launched the network within the following year (ASEAN, 2005).

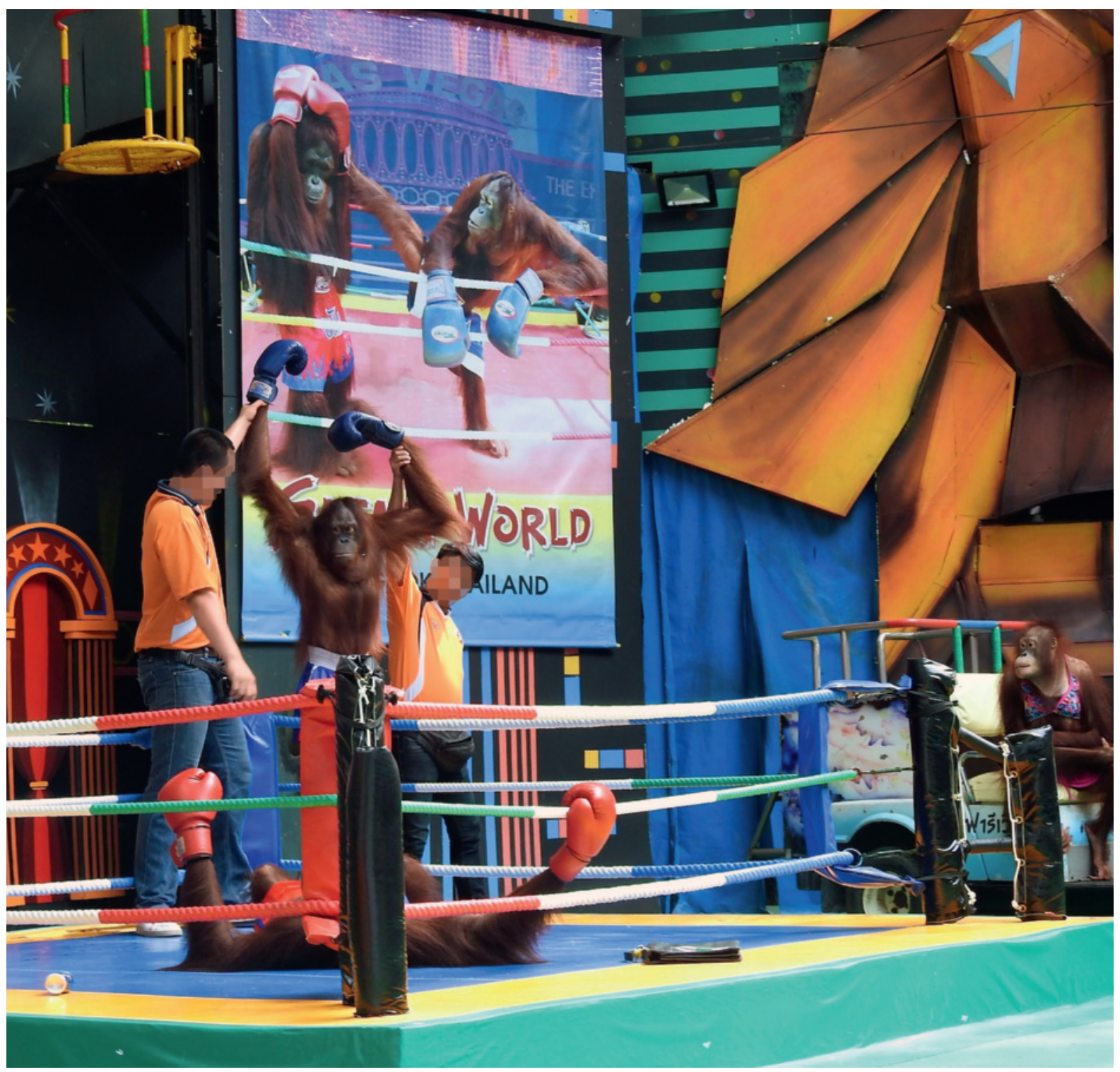


Standing in the way of the proposed network, however, was an enduring disagreement between Thailand and Indonesia over the orangutan trade, namely the question of where the orangutans in Thailand's entertainment industry originated. In 2005, months after the CITES COP, Thai and Indonesian delegations met to negotiate the repatriation of Safari World's orangutans back to Indonesia. This deal was to satisfy Indonesia and pave the way for the launch of the ASEAN Wildlife Law Enforcement Network (ASEAN-WEN or WEN). During the negotiations, Thai officers placed emphasis on money and image, and on who would accept responsibility for the trafficking and the resulting public outcry. At the 13th CITES COP late in 2004, the region's ministers had agreed that the cross-border trade in orangutans and other species was a shared problem and responsibility (ClickPress, 2006). While preparing the launch of ASEAN-WEN in 2005, the Thai minister of environment intervened in the orangutan negotiations by proposing to the Indonesian delegation that Thailand would pay to fly the apes back to Indonesia on a military cargo plane. The Indonesians accepted the offer and the impasse was broken.

The next few years saw a decline in the number of orangutan shows in Thailand. National WEN task forces stepped up enforcement. Over the following decade ASEAN-WEN seized US $\$ 150$ million in assets from wildlife criminals (Freeland, 2016). But some of ASEAN-WEN's funding was cut by 2015, when ASEAN member countries did not fulfil their commitments to cover the necessary financial and human resources for the WEN Secretariat. WEN law enforcement operations continued at a slower pace, while the influx of tourists into Thailand continued to grow and diversify. ${ }^{10}$ By 2014, orangutan shows were back in full force. Seats that had been filled by South Korean, Japanese, US and Western
European visitors until 2014 were subsequently filled by Chinese and Russian tourists, who may not have been exposed to awareness raising campaigns about orangutans. Shareholder reports from Safari World revealed US\$58 million in revenue for 2016, prompting investors to consider constructing another park in Phuket at a cost of US\$100 million; meanwhile, similar, smaller operations in Thailand, Cambodia, and Indonesia continued to source orangutans, tigers and elephants (Safari World, 2017; Silom Advisory Co., 2017).

In 2016, undercover agents working for Thai law enforcement helped Thai police to arrest traders in infant orangutans. Investigations carried out by Freeland throughout 2016 established that dealers were pricing the orangutans at US $\$ 10,000$ each-probably more than local businesses would pay. The 2016 investigation that resulted in these arrests shed light on a trafficking business that supplied most of the animals sourced in Indonesia (Gettleman, 2017). As of August 2019, the case was ongoing and, like so many other wildlife cases, it was moving slowly, delayed in the face of heavy caseloads and because trafficking crimes are accorded low priority.

Although zoos and theme parks prefer captive-bred orangutans, as acquiring them is both legal and more affordable, adult apes do not always breed well. Audiences are most interested in seeing young (juvenile and adolescent) apes, which may be driving the renewed appearance of infant orangutans in Thailand.

As long as any segment of the global public enjoys orangutans in entertainment, enforcement will only be able to make temporary dents in the trade. Safari World is counting on steady growth in the influx of tourists from ASEAN countries-which are home to more than 600 million people-as well as China, the Middle East and Russia to continue to pay for such experiences. A 
business risk assessment for shareholders contemplating expansion of the business mentions nothing about the potential negative impact of awareness raising campaigns (Silom Advisory Co., 2017). Yet, evidence indicates that consumer awareness programs have had an impact on targeted audiences in the past, and that they can be expected to work again if they are aimed at new audiences (Burgess et al., 2018; see Annex

\section{BOX 4.2}

\section{Demand Hot Spots in the Live Ape Trade}

Significant information gaps preclude an accurate assessment of the scale of the illicit ape trade as well as the number of apes kept as pets or in private collections. Most of the data is drawn from undercover investigations and analysis of the illegal trade conducted on social media and via online sales. What seems clear based on the available evidence is that the demand for illegally traded live apes stems primarily from private or personal collections (Clough and May, 2018). They are used as pets, gifts that confer status, and attractions at restaurants, hotels and private collections.

The private pet trade is principally located in Eastern Europe, the Middle East and Russia (J. Head, personal communication, 2018), and is focused almost exclusively on young animals. Most of the apes leave Africa or Asia for their destination countries smuggled on international airlines; established intermediaries and dealers whisk them through busy transit hubs and transfer them on for sale to their final buyers. In some cases, such as when the buyers are wealthy nationals from Gulf states, the apes are flown on private airplanes and pass unnoticed through border controls. The demand for protected species is also significant in the former Soviet states, where laws allow for private ownership of exotic species. Numerous private facilities, including restaurants and hotels, place acquired animals on display for the entertainment of their guests (Clough and May, 2018).

Wildlife crime specialist Mary Utermohlen reports that the United Arab Emirates (UAE) serves as a major transit hub and destination for trafficked wildlife (Utermohlen and Baine, 2018). Other major hubs include Cairo, Doha and Istanbul. In Kuwait, Qatar and the UAE, wealthy families keep young chimpanzees or gorillas as status pets. The Gulf states and Egypt are hotspots for the illegal trade in apes, partly because their location between Africa and Asia places them on the path of frequent flights and partly because they exhibit a strong demand for protected species, including live reptiles and birds, as well as wildlife products such as ivory, rhino horn and skins (Haslett, 2015).

This trade has been enabled by irregularities and corruption in the use and control of CITES permits from countries where the animals are sourced, and as a result of this greats apes such as bonobos and chimpanzees are being held by notorious wildlife traders and owners of private wildlife parks (Clough and May, 2018).
II). Infomercials and ads that feature local influencers who tell the true story of how orangutans are acquired and treated could influence tourist expectations, which may affect demand and persuade shareholders to halt the use of orangutans in the entertainment sector.

\section{Trafficked, "Saved" and Rescued: Pet Apes in Indonesia}

In numerous countries in Asia, Eastern Europe, the Middle East and the former Soviet Union, it is not uncommon for apes to be kept as pets. International demand for apes as pets poses direct challenges for their conservation (see Box 4.2 and the Introduction to this volume). This section analyzes the demand for orangutans in Indonesia, where the trade in these species continues even though they are protected under law (Freund, Rahman and Knott, 2017; Nijman, 2017b; Republic of Indonesia, 2018; Sánchez, 2015). ${ }^{11}$

Rescue centers across the country are often the last destination for domesticated orangutans, many of whom are confiscated from homes where they were kept as pets. Details on the number of orangutans arriving at rescue centers provide some insight into the extent to which orangutans are being kept as pets. Data compiled from three of the seven rescue centers currently operating in Kalimantan, in Indonesian Borneo, indicate that about 1,500 orangutans were rescued between 2001 and 2013 and that up to $60 \%$ of them were known or suspected to have been pets or domesticated in local villages (Sánchez, 2015). The rescue figure is probably an underestimate, as captive live apes and apes who have died typically go unreported. From 2005 to 2013, three of Indonesia's seven operating rescue centers for orangutans rescued an average of 107 individuals per 
year, three more per year than reported from 2000 to 2004 (Nijman, 2005a; Sánchez, 2015). This increase points to a rise in the number of orangutans kept as pets and shows that more orangutans are arriving at rescue centers despite collective efforts by governments and organizations to protect them.

\section{The Trade in Orangutans: Hunting, Trafficking and Market Value}

Research indicates that in Kalimantan, individuals who capture orangutans tend to do so opportunistically, rather than by design, although some trade networks are known to catch and smuggle orangutans mostly for the international wildlife trade. Farmers who shoot crop-raiding adults and hunters who kill them for food may collect unweaned orphans for sale on the live animal market. Encroachment into orangutan habitat due to forest conversion and illegal logging presents hunting opportunities and drives the illegal trade by encouraging human-wildlife contact, thus increasing the likelihood of conflict between people and apes (CampbellSmith et al., 2010; Nijman, 2009; Stiles et al., 2013; Utami-Atmoko et al., 2017; see Box 1.3).

As part of organised trade chains, captured orangutans are transported through villages into towns and cities along the coasts of Borneo and Sumatra, from where they are sent to Jakarta or cities farther afield, using cargo services on public trains, buses and ships, or private courier services. From these international hubs, they are transported by air to Malaysia, Thailand and other destinations (Nijman, 2009; Stiles et al., 2013). In 2014, customs officials intercepted a smuggling attempt of one infant orangutan and three gibbons at Jakarta International Airport (TRAFFIC, 2014). In the last few years alone, several orangutans appear to have been smuggled out of Indonesia and discovered as far afield as Kuwait (ANTARA News, 2017).

Local prices for individual orangutans stood at IDR 1.5-2.5 million (US\$100-170) in 2018; the farther an orangutan travels from the point of origin, the higher the price. In August 2017, when law enforcement officers confiscated two orangutans in a major city in Kalimantan, they revealed that traders had paid the hunter IDR 1.5 million (US\$100) for one and IDR 2.5 million (US\$170) for the other. The smugglers had intended to transport the two infant orangutans to the island of Java and sell them for IDR 50 million (US $\$ 3,400$ ). On the international market, orangutans have reportedly fetched US\$50,000 (Wyler and Sheikh, 2008).

\section{Local Ownership of Pet Orangutans in West Kalimantan}

The reasons and methods for acquiring pet orangutans vary across owners. In West Kalimantan, the southwestern province of Indonesian Borneo, the International Animal Rescue (IAR) Indonesia center in Ketapang conducted interviews with 127 former owners to gain insight into why and how people come to own orangutans. Fewer than onequarter of the respondents $(23 \%, n=29)$ said they had paid for their orangutan; nearly half $(48 \%, n=61)$ reported having "found" them in a clearing area of an oil palm plantation or taken the animals in after they or someone else had killed the mother. Respondents who said they had paid for their orangutan reported spending anywhere between IDR 500,000 and IDR 1.8 million (US $\$ 35$-US\$130) for an individual from a different province of Indonesian Borneo. In descending order of frequency, respondents' declared occupations were local palm oil worker, farmer, miner, fisherman, shopper, former soldier, pastor or priest, and police officer. 
Photo: In Kalimantan, local trade in orangutans is primarily opportunistic, does not involve trafficking syndicates and is not driven by significant economic incentives. Although all the respondents said they knew that orangutans were protected species, none cited that status as a reason for surrendering their pet.

The lack of fear of legal consequences indicates that law enforcement is weak. (C) IAR Indonesia Heribertus Suciadi
Given that the average monthly wage in Indonesia is IDR 2.3 million (US\$150), the price of an orangutan-an iconic, nationally protected species-is not significant (WageIndicator, n.d.). Indeed, these apes are sometimes more affordable than smaller protected primates. A slow loris (Nycticebus spp.), for example, can cost between IDR 300,000 and IDR 1 million (US $\$ 20-U S \$ 66$ ) at markets in Java's main cities. Rather than acting in the interest of financial gain, people who capture orangutans are thus more likely to be focusing on removing animals from situations that can lead to conflict, such as crop-raiding.

None of the respondents indicated that they had intended to acquire a pet ape, but the majority displayed a sense of entitlement about owning an orangutan, presenting themselves as the animal's rescuer. This savior complex did not translate into the provision of adequate welfare for the apes, however; many were kept in filthy, cramped conditions, given insufficient or unsuitable food, or simply chained up outside the house without protection. Betraying an erroneous understanding of animal welfare, owners spoke about having "saved" animals as a sufficient criterion for possessing them. There is little data available to explain how this notion arose or evolved.

IAR researchers hypothesize that the respondents' behavior stems from a perception of the animals as "cute" and similar to human babies. A former owner named Tere said of the orangutan she kept:

\footnotetext{
"He slept in our room. We made him a hammock. At night he asked for milk [...] just like a human baby. I cried when we were separated from him because we cared for him deeply, as though he were our own baby."
}

Certain owners anthropomorphized the apes, providing them with human food, washing them and dressing them as though they were human babies (Serpell, 2002).

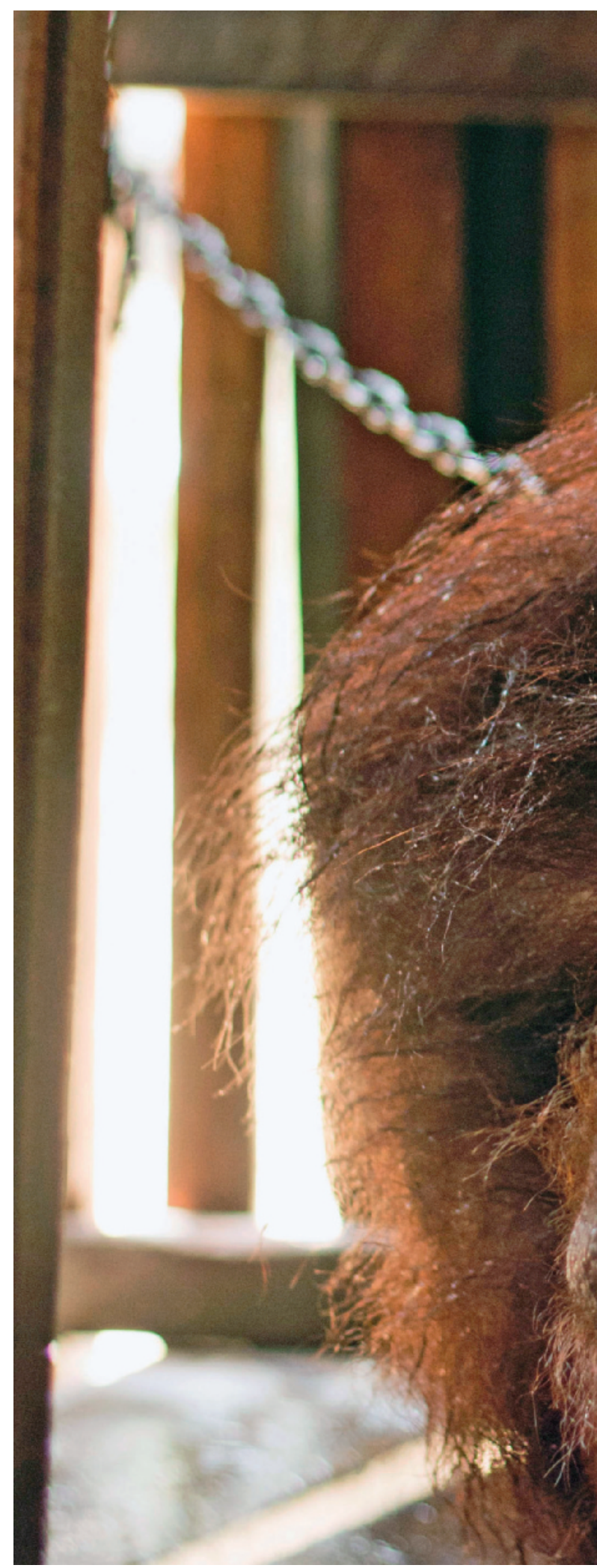




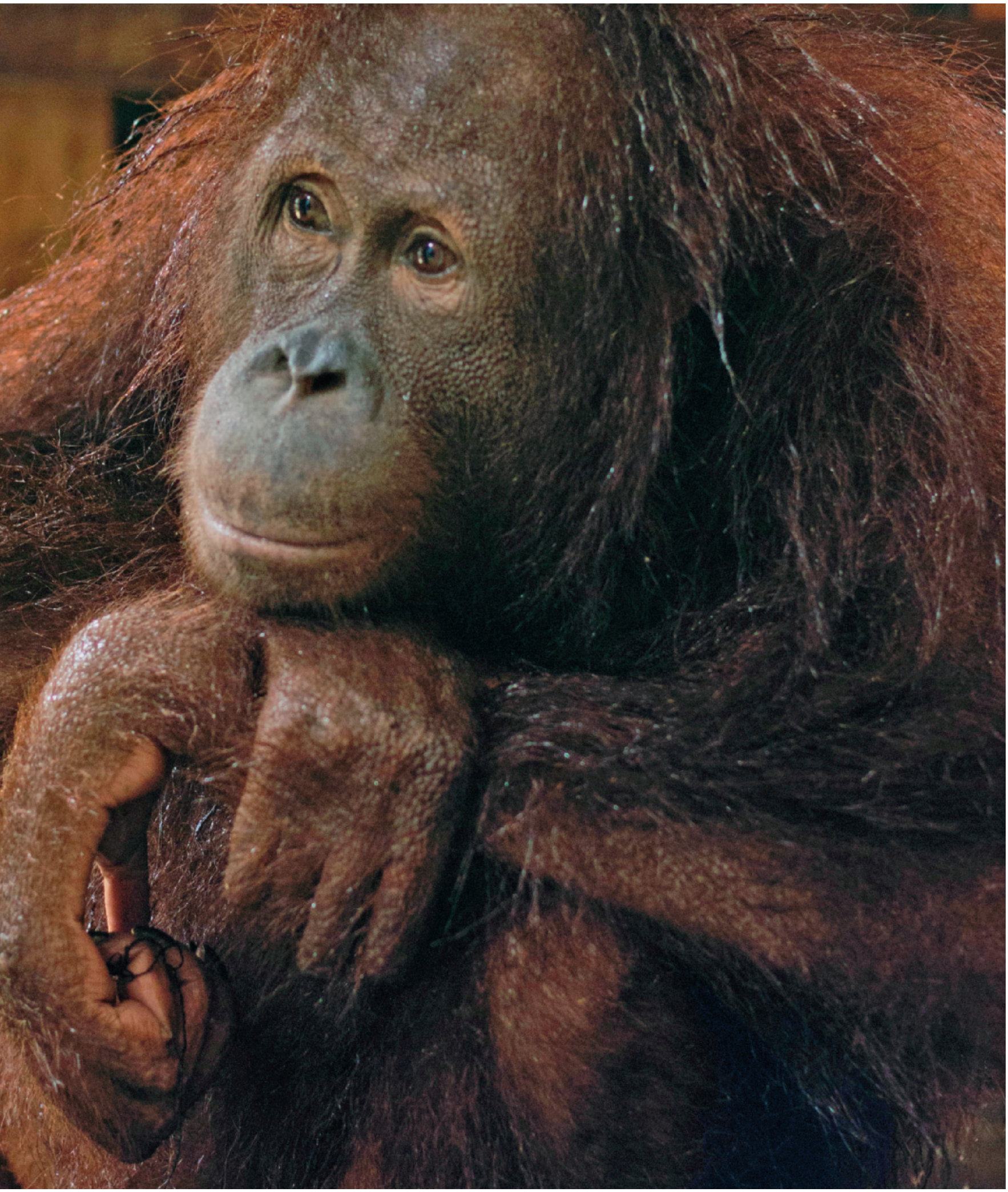


Growing

segments of the

global population

have been exposed

to online images and

videos that present

ape ownership and

direct interaction with

apes as desirable,

affordable and

attainable.
Some displayed pity for their pets, indicating that what they perceived as the orangutans' human-like behavior evoked a sense of affection.

Misconceptions of orangutans as tame, harmless creatures who are easy to keep may be linked to a desire to be perceived as a nurturer. Former owners appeared proud to have played this self-appointed role; they implied that doing so raised their social status among family, friends and the wider community. Yulita, another former owner, stated:

Someone told the authorities that we were

keeping an orangutan as a pet because they envied us. ${ }^{12}$

Owners also misunderstood the rescue, rehabilitation and release process, which they deemed to be a cruel act of abandonment whereby animals are returned to the wild and required to find their own food, fend for themselves and live without human love and compassion. After having nurtured apes for some time, many owners appeared to have blocked out or forgotten why these orphaned babies ended up in their care in the first place-namely that their mothers were killed. ${ }^{13}$

The majority of orangutan owners interviewed for this study kept orangutan babies and infants. Owners of larger, adult orangutans may have a different perspective, especially when their pets become aggressive and difficult to handle, at which point they may be more willing to surrender them. The study findings indicate that the local trade in orangutans is primarily opportunistic, does not involve trafficking syndicates and is not driven by significant economic incentives. Although all the respondents said they knew that orangutans were protected species, none cited that status as a reason for surrendering their pet. The lack of fear of legal consequences indicates that law enforcement is weak (Nijman, 2009; Shepherd, 2010).
Indeed, of the 229 orangutans received by the IAR center between 2009 and 2018, only three were turned over due to confiscations carried out by the authorities.

Social media plays a role in promoting the demand for live apes in Indonesia and elsewhere, in part by influencing perceptions of ape ownership. The next section explores this relationship.

\section{Social Media: Influencing the Demand for and the Perception of Apes}

The Internet enables easy, fast and ubiquitous communication and marketing that can influence behavior and desires. Growing segments of the global population have been exposed to online images and videos that present ape ownership and direct interaction with apes as desirable, affordable and attainable. While the impact of such portrayals on ape conservation may be significant, the same social media platforms present opportunities for tackling the illegal wildlife trade in apes and promoting conservation initiatives, including via social marketing designed to influence behavior (see the Introduction to this volume and Annex II).

\section{Social Media Platforms as Hideouts for Wildlife Traffickers}

Over the past few years, much of the trade in wildlife-both legal and illegal-has migrated to online forums and away from more traditional open markets (IFAW, 2008, 2014). Given the accessibility of the Internet around the world, wildlife traffickers can reach a large number of social media users very quickly (Krishnasamy and Stoner, 2016). Moreover, they can offer their goods in complete anonymity. Limited data are available 
on the prevalence of wildlife trade in "closed" social media groups and password-protected online forums, and it is difficult to monitor related transactions or evaluate the threats with any degree of accuracy (IFAW, 2014; Krishnasamy and Stoner, 2016). Previous research largely focused on wildlife trade conducted on openly accessible platforms, such as commercial trade portals and online auction sites, which lend themselves to public monitoring (IFAW, 2014). As awareness has grown about the illegal wildlife trade and as law enforcement efforts to curb it have intensified, traffickers appear to have moved underground (Krishnasamy and Stoner, 2016).

Online trade may have a particularly pernicious effect on wildlife in Asia, a region that is not only rich in threatened and restricted-range species, but also home to more than 2.3 billion Internet users and nearly 870 million Facebook users (Internet World Stats, n.d.). The photo-sharing app Instagram has gained significant momentum and now boasts more than 1 billion monthly active accounts, most of which are in Southeast Asia (Nguyen, 2018; Yuniar, 2016).

To gain a sense of the extent to which wild animals are sold on social media, the wildlife trade monitoring network TRAFFIC monitored 14 Facebook groups in Malaysia, where about 68,00o people are active users. As most of the monitored groups were "closed," TRAFFIC relied on inside contacts, who were able to access information on transactions. The study found that, over a five-month period in 2014-15, the groups advertised the sale of more than 300 wild animals representing about 80 species, including sun bears, otters, binturong, owls and gibbons. More than $60 \%$ of the species are native to Malaysia; almost half of them are protected from all aspects of hunting or trade (Krishnasamy and Stoner, 2016). In a later report focused on the illegal wildlife trade in Thailand, TRAFFIC demon- strates that Facebook continues to be used for the sale of critically endangered wildlife (Phassaraudomsak and Krishnasamy, 2018).

Facebook responded positively when presented with the results of both reports. A spokesperson said the social networking site would work with TRAFFIC to help put an end to the illegal wildlife trade in Malaysia and that it would remove all relevant content that violates its terms of use-including groups, posts and accounts. Facebook has since joined the Coalition to End Wildlife Trafficking Online and is working with TRAFFIC and partners to tackle the illegal wildlife trade (see pp.125-126). Despite these commitments, a growing number of wildlife traffickers appear to be active on Facebook in Malaysia, Thailand and many other places. Along with other social media platformssuch as Craigslist, eBay, Etsy, VKontakte and WeChat-Facebook could exert more control to prevent illegal sales of wildlife, including by providing law enforcement with the details of users who violate wildlife legislation.

\section{Gibbons as Pets and Props in the Social Media Marketplace}

The trade in gibbons, particularly in the genera Hylobates and Symphalangus, appears to be thriving at the national and international levels. The rapid growth and widespread use of social media facilitates the trade, which often occurs undetected. Evidence points to Indonesia and Malaysia as the two habitat countries with the most prolific illegal pet trade, predominantly in very young animals (see Figure 4.1).

Research conducted for this chapter from April to June 2018 identified 10 Facebook groups and 11 Instagram accounts that featured ads for gibbons, including 16 from Indonesia and 5 from Malaysia, most of them for sale in their habitat country. At least 50 individuals were selling infant gibbons.
Along with other social media platforms — such as Craigslist, eBay, Etsy, VKontakte and WeChat-Facebook could exert more control to prevent illegal sales of wildlife. 


\section{FIGURE 4.1}

\section{Gibbons for Sale on Social Media}

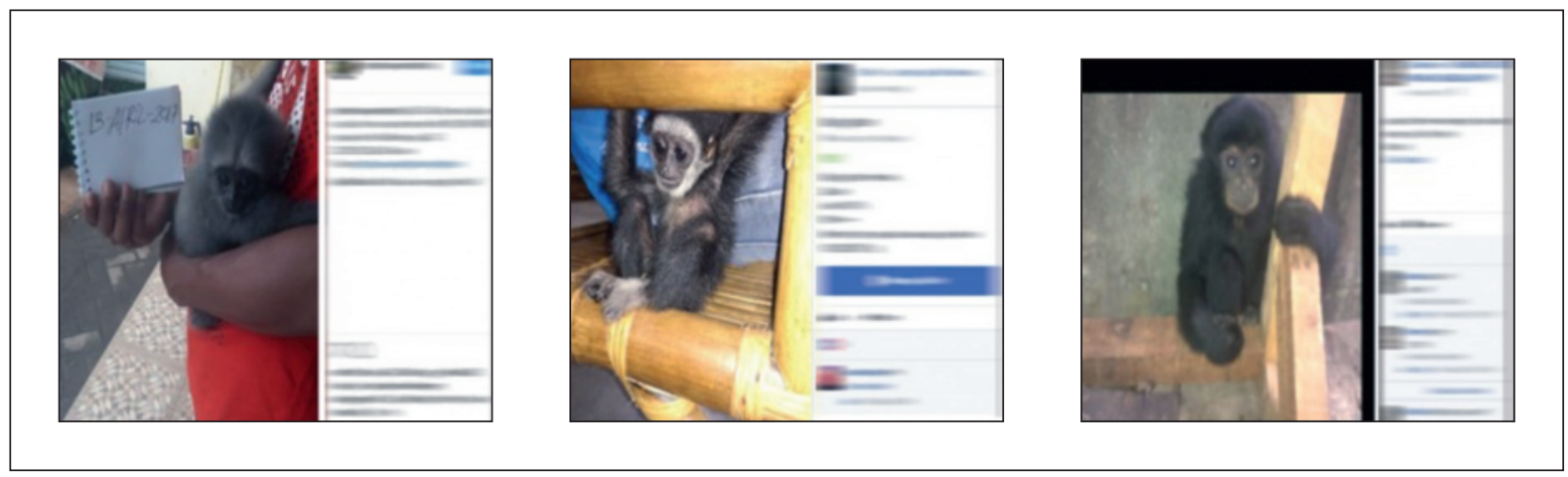

Sources: screenshots from 2017

A follow-up review was carried out in December 2018 (Cheyne, n.d.; see Table 4.1). In 50 reviewed ads, all gibbons were under three years of age. ${ }^{14}$ Online comments related mostly to the price and age of gibbons, or to their "cuteness." Further questions were directed to a WhatsApp number or sent via direct message. The gibbons cost between US\$150 and US\$540 (Cheyne, n.d.; Smith and Cheyne, 2017).

Thailand tops the list in terms of proffering wildlife as photo props for tourist self-

TABLE 4.1

\section{Ads for Gibbons in 10 Facebook Groups and 11 Instagram Accounts}

\begin{tabular}{|l|l|l|}
\hline \multirow{2}{*}{ Species for sale } & \multicolumn{2}{|c|}{ Number of ads } \\
\cline { 2 - 3 } & $\begin{array}{l}\text { April-June } \\
2018\end{array}$ & $\begin{array}{l}\text { December } \\
2018^{*}\end{array}$ \\
\hline Moloch gibbon (Hylobates moloch) & 18 & 24 \\
\hline Siamang (Symphalangus syndactylus) & 10 & 9 \\
\hline Lar gibbon (Hylobates lar) & 6 & 7 \\
\hline Müller's gibbon (Hylobates muelleri) & 4 & 4 \\
\hline Agile gibbon (Hylobates agilis) & 2 & 2 \\
\hline
\end{tabular}

Note: * It is not possible to determine whether any of the gibbons for sale in December 2018 were the same as those seen in April-June 2018. Some gibbons may have appeared in more than one ad.

Source: Smith and Cheyne (2017) ies and photo opportunities on beaches and in bars (Brockelman and Osterberg, 2015; see Figure 4.2). The gibbons used in this context are typically under two years of age.

The practice of sharing tourist selfies with gibbons on social media not only perpetuates the idea that it is appropriate to have photos taken with primates, but also fuels the demand for gibbons, and thus their removal from the forest. Similarly, social media images that portray wealthy and influential individuals with their pet apes suggest that owning an endangered animal is desirable and respectable. Such pictures also demonstrate that the law is enforced selectively (Malone et al., 2003). Such images may also influence the general understanding of the conservation status of apes in the wild (see Box 4.3).

A key challenge to reducing the online supply of wildlife is the inaccessibility of "closed" social media groups. For security and privacy reasons, companies retain exclusive control over the back-end of social media sites. Since these companies are not technically publishers, however, they are not required to edit content, even if it is illegal. Meanwhile, regulations and legislation governing social media lag behind online developments in the illegal wildlife trade 
FIGURE 4.2

\section{Gibbons as Photo Props for Foreign Tourists on Thai Beaches}

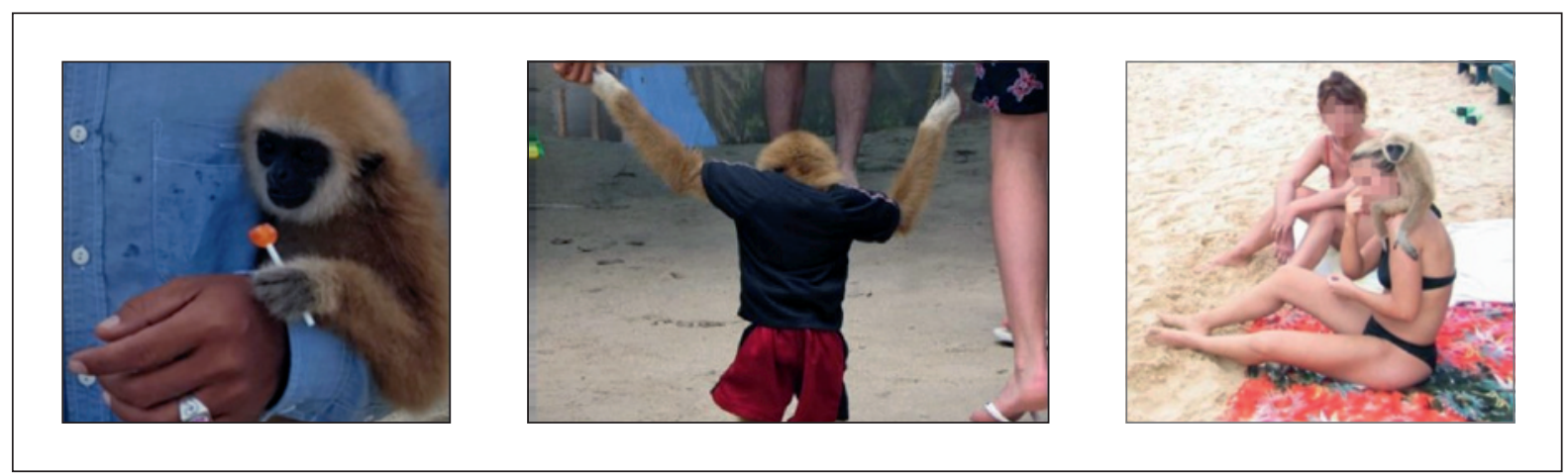

Sources: screenshots from 2018

\section{BOX 4.3}

\section{Portrayals of Apes and Their Influence on Conservation Action}

Some research shows that large, charismatic species such as great apes receive more conservation attention and funding than smaller, less well-known taxa, such as invertebrates and amphibians (Sitas, Baillie and Isaac, 2009). At the same time, however, the widespread use of apes on social media and in the marketing and entertainment sectors has impaired efforts to conserve them (Courchamp et al., 2018). While a dearth of data makes it difficult to quantify the impact of such portrayals on the conservation of great apes and gibbons, it is clear that biased and inaccurate representations of these taxa affect people's perceptions of their prevalence. Indeed, assessments of "virtual populations" influence the degree to which the public is concerned about a species' survival (see Case Study 4.1).

In 2005, a brief visitor study conducted in accredited US zoos revealed that the public was significantly less likely to consider chimpanzees endangered in the wild than other great apes, such as gorillas (Ross et al., 2008). Respondents consistently justified their reasoning by indicating that chimpanzees were so prevalent in movies, television shows and ads that they could not possibly be under threat. Subsequent investigations demonstrated that the manner in which chimpanzees are portrayed influences the public's opinion of their conservation status (Ross, Vreeman and Lonsdorf, 2011). People who were shown digitally altered images of a chimpanzee standing in a common man-made setting, such as an office space, tended to characterize wild populations as healthy, stable and certainly not in need of conservation attention. Likewise, those who viewed images of chimpanzees in direct contact with humans concluded that they would make viable pets. These and other studies provide compelling evidence that portrayals of apes have a substantial influence on the public's perception of these species and that they restrain support for conservation efforts (Leighty et al., 2015; Schroepfer et al., 2011).

Since that initial visitor survey in 2005, progress has been made in curtailing the use of inaccurate portrayals of primates. In the United States, virtually all of the "actor" chimpanzees who had been maintained for use in the entertainment industry have been re-homed in accredited zoos and sanctuaries (ChimpCARE, n.d.-a; Roylance, 2010). Meanwhile, the use of stock photos that display chimpanzees in unnatural poses and settings has also fallen out of favor, perhaps signaling an end to the all-too-common "grinning chimpanzee" photos on greeting cards (Cho, 2016; Djudjic, 2017). All told, the country has experienced a seismic shift in attitudes towards the use of apes in the entertainment sector (see Box 4.1).

Despite such progress, however, there is a need for continued vigilance, particularly as inappropriate portrayals of apes continue to distort public perceptions, and as ape habitats from Africa to Asia remain under threat from ongoing human encroachment and exploitation. One of the tools at the disposal of conservation advocates is holding corporate entities accountable for releasing or posting outputs that undermine conservation efforts, whether intentionally or unintentionally. Another tool is the strategic use of traditional and social media to inform and correct public perceptions of apesand to impart an understanding of their conservaton needs (Silk et al., 2018). The revenue raised through the sale of images of threatened animals could be earmarked to pay for conservation efforts, which would help to turn "competition into cooperation between virtual and real populations" (Courchamp et al., 2018, p. 9). Such approaches can leverage the indisputable power of new media to strengthen ape conservation efforts. 


\section{CASE STUDPY 4.1}

\section{British News and Social Media Portrayals of Orangutans and Threats to Their Habitat ${ }^{15}$}

Orangutans make frequent appearances in the media in Britain, featuring regularly in national newspapers, magazines and television programs, as well as on websites and social media. While distinct in nature and oriented towards different audiences, these media outlets overlap considerably and can thus be understood as lying on the same broad continuum.

Most of these portrayals show charismatic, young orangutans juxtaposed with images of habitat destruction. The most commonly shown apes are orphans living in rescue and rehabilitation centers in Borneo or Sumatra. They are easily photographed in the open, often playing with each other or being trained in "jungle school" (Curran, 2018). They are also commonly pictured interacting with their human carers, especially when being cuddled or fed. Such images are extremely popular, drawing public attention to orangutan causes and generating donations and "adoptions" for orangutan charities (Palmer, 2018, p. 60). Portrayed as full-blown characters with names, biographies and personalities on rescue center websites, television documentaries and social media posts, these orangutans represent both the tragedy of extinction and the hope for a better future-in their case, an idealized journey "back to the wild." Their symbolic potency derives from what is often depicted as their dual nature: their simultaneous likeness to humans and their status as wild animals (Chua, 2018b; Russell, 1995).

These compelling images are commonly set against pictures of environmental destruction, which underscore the extent and urgency of the plight of orangutans. Particularly widespread are photographs of deforestation, oil palm plantations and their by-products, such as forest fires. News headlines-such as "Now or Never' Battle to Save Indonesia's Endangered Orangutans as British Companies Still Using 'Dirty' Palm Oil”-draw a






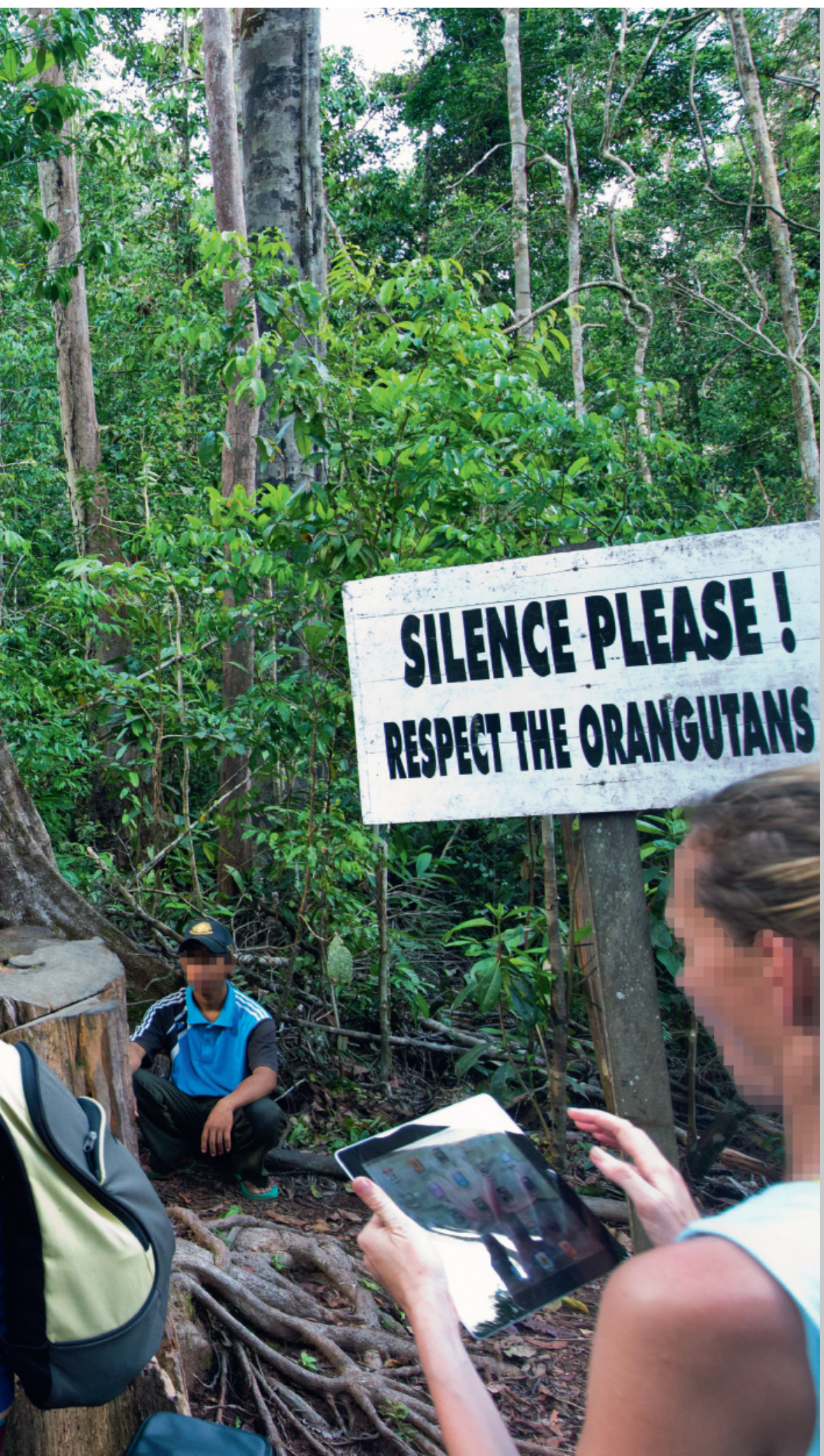

direct causal link between environmental destruction and the fate of their orangutan victims (Dalton, 2018). Unlike cute photographs, these images elicit horror and anger, with the aim of galvanizing viewers into taking action against corporations and governments. In this way, the visual tropes of cute orangutans and environmental destruction constantly invoke and reinforce each other, thereby generating a powerful narrative ("palm oil kills orangutans") that has come to dominate media portrayals of orangutans (Chua, 2018a).

\section{Distortions and Unintended Effects}

The influence of the dominant narrative can be seen in the growth of consumer movements against ("dirty") palm oil and large corporations' responses to them. A recent example is the supermarket chain Iceland's much-hyped Christmas 2018 television ad, which consists almost entirely of Greenpeace's short Rang-tan animation (Greenpeace, 2018; Iceland, 2018). It depicts a baby orangutan entering and messing up a girl's bedroom, before explaining that "there's a human in my forest" who is destroying the ape habitat for palm oil. The advertisement ends by reiterating Iceland's pledge to remove palm oil from all its own products "until all palm oil causes zero rainforest destruction." Denied clearance by the ad clearing body, Clearcast, because of its link to Greenpeace (classed as a body with political objectives), the ad garnered more than 65 million views online in the month after it was released on social media (Hickman, 2018). Many consumers responded with supportive messages, declaring that they were going to boycott all palm oil as a result.

This narrative, however, presents an oversimplified picture of current debates about palm oil and oil palm plantations; it also leaves out the many complex factors that shape the fate of orangutans and their habitat, including threats such as hunting, killing in retaliation for "crop-raiding" and the pet trade (Meijaard et al., 2011a, 2018; Voigt et al., 2018). While not unconnected to the expansion of industrial agriculture, these threats occur on a different scale and demand distinct mitigation strategies. Moreover, the media's unnuanced 
depiction of rehabilitation programs glosses over the controversies surrounding such projects, notably their long-term effectiveness and viability (Palmer, 2018; Rijksen and Meijaard, 1999; Wilson et al., 2014a). Although such programs represent only one component of orangutan conservation, their popularity risks channeling public attention and potential donations away from other longer-term, holistic efforts, such as habitat protection. ${ }^{16}$

The visual prominence of orangutans in these narratives can also have damaging knock-on effects. Although organizations strive to illuminate the wider environmental context behind these pictures, they cannot always control their dissemination and reinterpretation. Such images are frequently picked up and circulated, especially on social media, for their cuteness or amusement value. As they become unmoored from their explanatory text, two main problems arise.

First, the decontextualized circulation of "cute" orangutan images risks normalizing an already long-running perception of orangutans as performers or playthings rather than as wild animals (Aldrich, 2018; Cribb, Gilbert and Tiffin, 2014, chapters 7-8). This is compounded by the popularity of images of human-orangutan intimacy (such as orangutans clinging to carers), which risk cultivating the assumption that humanorangutan contact is acceptable or even desirable.

Although organizations try to challenge such perceptions, their messages do not always reach the wider public. As reviews on sites such as Tripadvisor suggest, many tourists arrive in Indonesia, Malaysia and elsewhere with precisely this image of cute, cuddly orangutans in mind (TripAdvisor, n.d.). Zoos and tourism-oriented wildlife centers have responded to-and arguably generated-this idea by promoting various orangutan encounters. In Indonesia, some of these facilities have been criticized for appearing more like tourist attractions than rehabilitation centers (Danaparamita, 2016). Centers such as Bukit Lawang, Semenggoh, Sepilok and Tanjung Puting offer tourists opportunities to take photographs of orangutans at their feeding platforms. Both Bali Zoo and Singapore Zoo sell "breakfast with orangutans" packages that allow visitors to have a meal a few meters away from orangutans and take photographs in close proximity to them (Singapore Zoo, n.d.; Viator, n.d.). Although physical contact is widely prohibited, this rule is difficult to enforce in practice (Palmer, 2018, chapter 6). Indeed, it is not uncommon for videos and photographs of tourists touching, carrying or hugging orangutans to circulate on social media. A vicious cycle thus ensues, with such images further perpetuating misleading perceptions of orangutans, while fanning demand for live apes to sustain these activities (Moorhouse et al., 2015). In this way, even the most well-meaning representations of orangutans can inadvertently contribute to the conditions that sustain the ape trade in Southeast Asia.

Second, the appearance of such images on television and social media can produce unintended effects among
Indonesian and Malaysian audiences and users. As Meijaard and Sheil (2008) note, orangutan conservation schemes can spark resentment among villagers who see conservationists as caring more about animals than humans. Photographs of orangutans being cuddled and fed in rehabilitation centers risk aggravating such sentiments and generating accusations of double standards from local people, as well as exacerbating tensions over conservation schemes (Palmer, 2018, p. 214). In this way, such images can have detrimental consequences in the very areas where local collaboration is most needed.

\section{Addressing the Problems}

Action is needed on different fronts. First, producers of source material, such as orangutan charities and journalists, could exercise more caution with respect to potential unintended effects of their images and narratives-for example, by ensuring that the popular focus on the cute and cuddly aspects of these apes does not skew public perceptions of them. A reassessment of the extent to which images play up the human-orangutan bond is also in order, particularly in organizations that display photographs of their founders and staff interacting with orangutans - without any protection - on their websites and in publicity material. While such images can be elements of a successful marketing strategy, they can also undermine efforts to redress the misconceptions that fuel the live ape trade. Addressing these content-based issues will necessitate coordination among orangutan organizations, which currently observe varied guidelines; by joining forces, they will be better positioned to issue consistent messages and to avoid undermining each other.

Rather than changing the content of media portrayals, it is important to address the structural conditions in which they exist. For example, it is worth asking which media circuits such images and narratives travel across, and what effects they have as they move. Such an approach would require coordination between international conservation organizations and their partners in Indonesia and Malaysia. It would also involve identifying new partnerships (such as with tour operators or national celebrities) and channels for action (such as Indonesian social media campaigns) through which to disrupt misleading narratives and generate new ones. Such a joined-up approach would help tackle the effects-and not just the contents-of media distortions. 
(see Box I.5). As noted above and discussed below, engagement with social media holds some promise; progress has been made with Instagram, which now monitors images taken with wildlife (see Box I.5).

Efforts are also needed to reduce consumer demand for gibbons as pets and props. Initiatives that aim to curb the pet trade can usefully target the main purchasers of apes, the emerging Indonesian and Malaysian middle classes and, in particular, 20-25 year olds who have disposable income and live in cities. Campaigns that target foreign tourists could help to reduce the use of gibbons as photo props. ${ }^{17}$ In particular, tourists could influence perceptions and awareness of threatened species (Nekaris et al., 2013).

\section{How Online Companies Can Help to Tackle Wildlife Trafficking}

As discussed above, the trade in endangered species has expanded from physical marketplaces and storefronts to web-based platforms (Kramer et al., 2017). Not only does this shift allow sellers to access a far greater number of potential customers, but it also affords them a higher level of anonymity and risk mitigation since they can more readily hide behind fake accounts. Illicit sales often take place on social media platforms through posts and private messaging features, as well as through traditional e-commerce websites with built-in buying and selling functionality.

After first recognizing this issue in 2004, TRAFFIC sought to address it across online platforms starting in 2012, initially by engaging Chinese Internet giants (TRAFFIC, 2012; Williamson, 2004). By 2016, the organization was partnering with the World Wide Fund for Nature (WWF) and the International Fund for Animal Welfare (IFAW) to convene the tech sector globally and raise awareness of the illegal wildlife trade, encourage sector-wide collaboration and develop solutions (TRAFFIC, personal communication, 2019).

WWF, TRAFFIC and IFAW launched the Coalition to End Wildlife Trafficking Online on March 7, 2018 to reduce wildlife trafficking online through industry collaboration. By June 2020, the number of members had increased from 21 global companies to 36 (WWF, 2018, n.d.). ${ }^{18}$ Through the Coalition approach, companies work with IFAW, TRAFFIC and WWF to develop an action plan tailored to their unique platforms to track progress towards reducing illegal wildlife trade on their sites. In a progress report released in March 2020, the Coalition revealed that its members had blocked or removed more than 3.3 million listings that violated wildlife policies (The Coalition, 2020).

Given social media's unique ability to influence billions of users across the globe, the Coalition's user education component is an essential part of reducing wildlife trafficking through messaging and social applications. Since many users of social media are likely to respond to and share content without fully understanding its origins, it is important to draw a connection between the use and acquisition of live animals and wildlife trafficking (TRAFFIC, personal communication, 2019).

In December 2017, TRAFFIC and WWF launched a pop-up alert system with Instagram to educate users about searched content that may be linked to the illegal trade in live animals, as well as their parts and products (Instagram, 2017). The two organizations provided about 250 hashtags (\#) that may be associated with the illegal trade and related activities, including selfies with wildlife. Users who use the targeted hashtags to search for content receive an alert providing more information about the issue as well as a link to the Instagram help 


\section{FIGURE 4.3}

Instagram Alert about the Illegal Wildlife Trade, Initiated on December 4, 2017

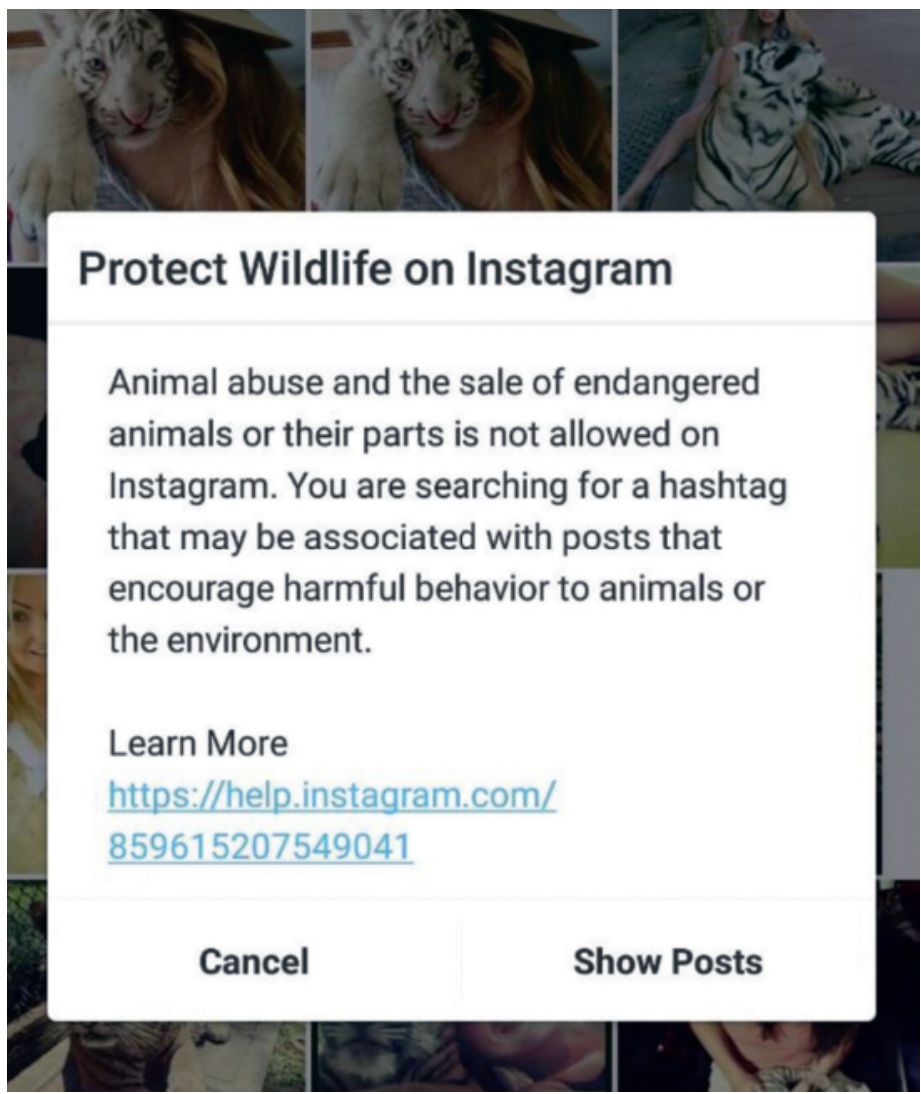

Source: Instagram screenshot from 2018

Photo: Awareness raising campaigns could be used to stem the demand for wildcaught apes in Thailand, particularly by targeting tourists with the aim of curbing the popularity of orangutan shows and the use of apes as props for selfies. (C) Paul Hilton/ Earth Tree Images page to learn more (Instagram, n.d.-a; see Figure 4.3).

This pop-up alert has two primary objectives. The first is to educate users about posts that may be linked to wildlife trafficking. Such posts may involve the sale of unsustainably or unverifiably sourced live animals, the promotion of animal selfies at tourist sites, or trafficking of illegally sourced wildlife products. Posts that openly advertise the sale or use of animals may lead users to assume that related transactions would be legal. Such was the case when videos of a "cute" slow loris being tickled went viral. Although the species is threatened with extinction and is listed on CITES
Appendix I, these animals rode the social media wave to fame as desirable pets (CITES, n.d.-b, n.d.-d). Many viewers probably assumed the primate raised his arms to enjoy being tickled, not understanding that this natural behavior was in fact a defensive movement (Nekaris et al., 2013). The popup alert that users receive when they search for \#slowloris aims to prevent them from unknowingly facilitating this illegal trade.

The second objective of the alerts is to deter criminals from using the platform to conduct illegal activities. For sellers who previously operated with impunity, popups announce Instagram's commitment to action on posts that violate company wildlife policies.

While pop-up alerts may represent a strong start to tackling online wildlife trafficking, the evolving nature of the illicit trade calls for additional, adaptable responses and preventive measures across the sector. In 2019, Facebook strengthened its wildlife policy by prohibiting adveritising of all species listed on CITES Appendix I and all live animals except those for sale by verified sellers. Coalition members are advised to continue their educational efforts while strengthening policy enforcement and enhancing automated solutions to detect and prevent illegal wildlife posts.

\section{Conclusion}

Most organizations that work to combat the illegal trade in live apes have relied heavily on bans and law enforcement, with great effort invested in the prevention of poaching and the capture of poachers, traffickers, transporters and various other actors who are involved in the supply chain (World Bank Group, 2016). The continued decline in ape populations and the ongoing loss of ape habitat cast doubt on the effectiveness of this approach as a core solution. While 
Most organizations that work to combat the illegal trade in live apes have relied heavily on bans and law enforcement. there is arguably a need to impose more penalties and launch more prosecutions to stem the supply of wild-caught apes, there is a pressing need to tackle the demand that drives the trade.

As this chapter demonstrates, much of the local demand for pet orangutans in Indonesian Borneo is fueled by misperceptions of apes' basic needs, rather than hopes of financial gain. Advocacy campaigns may have a role to play here-as they did in the United States, where they helped to tackle the demand for ape performers in the entertainment industry. In Indonesia, effective demand-reduction measures would cut down on the number of orangutans caught as a by-product of hunting and forest loss. Awareness raising campaigns could similarly be used to stem the demand for wildcaught apes in Thailand, particularly by targeting tourists with the aim of curbing the popularity of orangutan shows and the use of apes as props for selfies.

Global zoological associations can partner with Chinese zoos and wildlife parks-as well as local regulatory bodies-to enhance the welfare of captive apes, such as by providing guidance on preventing hybridization and reducing fetal and infant mortality rates. Lowering these rates, and thus maintaining the desired number of infants, has the co-benefit of reducing the demand for more wild-caught infants. Emerging shifts among Chinese people's attitudes towards wildlife indicate that the country may soon favor more concerted conservation efforts and stricter policies on the welfare of apes.

By facilitating and promoting the illegal ape trade, social media present both a challenge and an opportunity. Collaboration between conservation organizations and social media companies has already led to the development of pop-up alerts and user education programs. Tougher policies and additional measures-including the reporting of violations to law enforcement authorities- could go a long way towards reducing the demand for apes as pets, props and entertainers in today's wildlife crime hotspots and beyond.

\section{Acknowledgments}

Principal authors: Helga Rainer, ${ }^{19}$ Annette Lanjouw, ${ }^{20}$ Karmele Llano Sánchez ${ }^{21}$ and Graham L. Banes ${ }^{22}$

Contributors: Susan M. Cheyne, ${ }^{23}$ Liana Chua, ${ }^{24}$ Julia Gallucci, ${ }^{25}$ Steven Galster, ${ }^{26}$ Giavanna Grein, ${ }^{27}$ Steve Ross $^{28}$ and Penny Wallace ${ }^{29}$

Box 4.1: Julia Gallucci

Box 4.2: Annette Lanjouw

Box 4.3: Steve Ross

Case Study 4.1: Liana Chua

\section{Endnotes}

1 This section is based on the personal observations of G.L. Banes, who lived and worked in China from 2013 to 2016 and visited more than 180 zoos.

2 Based on informal conversations with zoo staff and permits seen by the author.

3 The two lone silverbacks are housed in Zhengzhou Zoo, Henan province, and in Jinan Zoo, Shandong province; the Shanghai Zoo has a group of gorillas.

4 The AZA does provide Japanese and Spanish translations of its chimpanzee care manual, however (AZA Ape TAG, 2010; TAG de Simios de la AZA, 2010).

5 Information included in Steve Martin's contract with Microsoft, 2015, seen by the authors.

6 Information from an internal tracking document at PETA, compiled by J. Gallucci.

7 This section reflects observations of Steven Galster, who, together with staff from the organization Freeland, began to monitor the use of great apes in the Thai entertainment sector in 1999 and helped broker bilateral government negotiations that led to the repatriation of smuggled orangutans from Thailand to Indonesia.

8 Based on Freeland observation of GovernmentNGO meetings in Jakarta and Bangkok in 2002, 2003, 2004 .

9 Based on Freeland annual observations of shows in Bangkok and Phuket.

10 Freeland annual spot check surveys at shows in Bangkok and Phuket. 
This section presents data from an ongoing study by International Animal Rescue (IAR) Indonesia that is looking at people's motivations for keeping orangutans as pets, as well as factors that influence this behavior. The data were collected during interviews with owners of pet orangutans before, while or after the apes were rescued by IAR and the BKSDA (Natural Resources Conservation Agency of the Ministry of Environment and Forestry of Indonesia). The study started in 2012.

section presents data from an ongoing study by International Animal Rescue (IAR) Indonesia that is looking at people's motivations for keeping orangutans as pets, as well as factors that influence this behavior. The data were collected during interviews with owners of pet orangutans before, while or after the apes were rescued by IAR and the BKSDA (Natural Resources Conservation Agency of the Ministry of Environment and Forestry of Indonesia). The study started in 2012.

13

位 by International Animal Rescue (IAR) Indonesia that is looking at people's motivations for keeping orangutans as pets, as well as factors that influence this behavior. The data were collected during interviews with owners of pet orangutans before, while or after the apes were rescued by IAR and the BKSDA (Natural Resources Conservation Agency of the Ministry of Environment and Forestry of Indonesia). The study started in 2012.

to End Wildlife Trafficking Online-which is convened by WWF, TRAFFIC and IFAW-were: 58 Group, Alibaba, Artron, Baidu, Baixing, Deine Tierwelt, eBay, Etsy, Facebook, Google, Huaxia Collection, Hantang Collection, Instagram, Kuaishou, Kupatana, Mall for Africa, Leboncoin, letgo, Microsoft, OfferUp, OLX, Pinterest, Poshmark, Qyer, Rakuten, Ruby Lane, Sapo, Shengshi Collection, Sina, Sougou, Tencent, Tortoise Friends, Wen Wan Tian Xia, Zhong Hua Gu Wan, Zhongyikupai and Zhuanzhuan (WWF, n.d.).

19 Arcus Foundation (www.arcusfoundation.org).
21 International Animal Rescue (www.internationalanimalrescue.org).

22 Wisconsin National Primate Research Center (www.primate.wisc.edu).

23 Borneo Nature Foundation (www.borneonaturefoundation.org/en/).

24 Brunel University London (www.brunel.ac.uk/anthropology).

25 People for the Ethical Treatment of Animals (www.peta.org).

26 Freeland (www.freeland.org).

27 TRAFFIC (www.traffic.org).

28 Lincoln Park Zoo (www.lpzoo.org) and Project ChimpCARE (www.chimpcare.org).

29 TRAFFIC (www.traffic.org). 